\title{
RNA G-quadruplex structure contributes to cold adaptation in plants
}

Xiaofei Yang ${ }^{1} \dagger$, Haopeng $\mathrm{Yu}^{1,2} \uparrow$, Susan Duncan ${ }^{1}$, Yueying Zhang ${ }^{1}$, Jitender Cheema ${ }^{1}$, J. Benjamin Miller $^{3}$, Jie Zhang ${ }^{1}$, Chun Kit Kwok ${ }^{4,5}$, Huakun Zhang ${ }^{2 *}$, Yiliang Ding ${ }^{1 *}$

\begin{abstract}
Nucleotide composition is suggested to infer gene functionality and ecological adaptation of species to distinct environments. However, the underlying biological function of nucleotide composition dictating environmental adaptations is largely unknown. Here, we systematically analyzed the nucleotide compositions of transcriptomes across 1000 plants (1KP) and their corresponding habitats. Intriguingly, we found that plants growing in cold climates have guanine $(\mathrm{G})$-enriched transcriptomes, which are prone to forming RNA G-quadruplex structures. Both immunofluorescence detection and in vivo structure profiling revealed that RNA G-quadruplex formation in plants was globally enhanced in response to cold. Cold-responsive RNA G-quadruplexes strongly enhanced mRNA stability, rather than affecting translation. Disruption of individual RNA G-quadruplex promoted mRNA decay in the cold, leading to impaired plant cold response. Therefore, we propose that plants adopted RNA G-quadruplex structure as a molecular marker to facilitate their adaptation to the cold during evolution.
\end{abstract}

1. Department of Cell and Developmental Biology, John Innes Centre, Norwich Research Park, Norwich NR4 7UH, United Kingdom

2. Key Laboratory of Molecular Epigenetics of Ministry of Education, Northeast Normal University, Changchun 130024, China

3. School of Biological Sciences, University of East Anglia, Norwich Research Park, Norwich NR4 7TJ, United Kingdom

4. Department of Chemistry and State Key Laboratory of Marine Pollution, City University of Hong Kong, Kowloon Tong, Hong Kong SAR, China

5. Shenzhen Research Institute of City University of Hong Kong, Shenzhen 518057, China

* Corresponding author. Email: yiliang.ding@jic.ac.uk (Y.D.); zhanghk045@nenu.edu.cn (H. Z.)

$\uparrow$ These authors contributed equally to this work. 


\section{Main Text:}

The earth's prodigious biodiversity was established in part by adaptation to diverse ecological habitats, driving speciation (1). In particular, plants are highly evolved to their specific environments, partly due to their sessile nature, with diversity across environments enabling their global colonization $(2,3)$. Varied nucleotide compositions were suggested to affect plant adaptations to specific habitats $(4$, 5). However, understanding of the underlying molecular mechanisms remains unclear.

The recent generation of transcriptome sequences of over 1000 plants (The 1000 plants initiative, $1 \mathrm{KP}$ ) allows us to systematically assess the biological significance of nucleotide compositions across the plant kingdom (6). We analyzed the frequency of the four nucleotides (A: adenine, U: uracil, C: cytosine and G: guanine) over all the major clades of land plants, including dicots, monocots, gymnosperms, ferns, lycophytes and bryophytes (Fig. 1A and Table S1). Overall, the frequencies of both $\mathrm{G}$ and $\mathrm{C}$ were consistently lower than those of $\mathrm{A}$ and $\mathrm{U}$ (Fig. 1A). Frequencies among four nucleotides varied much more in the 3'UTR compared to 5'UTR and CDS (Fig. 1A). We then obtained habitat locations of these plants from the Global Biodiversity Information Facility (GBIF) and extracted the corresponding 19 associated bioclimatic variables for these habitats from the WorldClim database (fig. S1A and Table S2, see Methods) (7). We calculated the Pearson Correlation Coefficient (PCC) between the transcriptomic nucleotide frequencies and bioclimatic variables primarily concerned with temperature and precipitation (i.e. BIO1: annual mean temperature, BIO12: annual precipitation; full list in Methods). PCCs between nucleotide frequency and temperature bioclimatic variables (BIO1BIO11) were overall stronger than those between nucleotide frequency and precipitation bioclimatic variables (BIO12-BIO19, fig. S1A), suggesting a stronger relationship between transcriptomic nucleotide composition and temperature of plant habitats. A and $U$ frequencies are mostly positively correlated with temperature bioclimatic variables, while $\mathrm{G}$ and $\mathrm{C}$ compositions are mostly negatively correlated (fig. S1B). The profound negative correlation between $G$ frequency and temperature bioclimatic variables was notable, indicating an enrichment of $\mathrm{G}$ in species growing in cold climates (fig. S1B).

Given that a G-rich region in an RNA molecule is capable of folding into a tertiary RNA structure called RNA G-quadruplex (RG4), involving both Hoogsteen and Watson-Crick base pairs (8), we therefore hypothesized that G-enriched transcriptomes from plants prevalent in colder climates may be complemented with RG4 motifs. We then calculated the RG4 frequency across the 1KP dataset, with a median frequency value of 1.27, 2.35 and $0.99 \mathrm{RG} 4 \mathrm{~s} / \mathrm{kb}$ of RG4 for 5' UTR, CDS and 3' UTR, respectively (Fig. 1B and Table S3). Across all genic regions, the overall correlations between RG4 frequency and temperature bioclimatic variables were significantly negative, whist generally less significant correlations between RG4 frequency and precipitation bioclimatic variables were observed (Fig. 1B and 1C), suggesting that RG4 is more strongly enriched in plant species growing in colder climates. 
To understand the underlying mechanisms of higher RG4 enrichment in plant adaptation to cold, we first visualized RG4 in cells from the model plant Arabidopsis thaliana, using the BG4 antibody, which is able to detect RNA G-quadruplex in cells (9). We found a significant increase and enhancement of cytosolic BG4 foci in the cold at $4^{\circ} \mathrm{C}$, compared to the normal temperature control at $22^{\circ} \mathrm{C}$ (Fig. $2 \mathrm{~A}, P$ $=10^{-4}$, by Student's t-test). The increase of the BG4 foci in the cold mimicked RG4 stabilization using the well-characterized pyridostatin ligand (PDS) (Fig. 2A, $P=10^{-6}$ by Student's t-test) (10), indicating that cold promotes RG4 folding in plant cells. Notably, when cold-treated plants were returned to $22^{\circ} \mathrm{C}$ for two hours, BG4 signals recovered to a similar level to that before cold treatment (Fig. 2A, $P=0.17$ by Student's t-test).

We then determined the in vivo folding status of individual RG4-motifs in the cold using SHALiPEseq, a high throughput method for RG4 detection (11). SHALiPE-seq is based on the preferable modification of the last $\mathrm{G}$ residues of G-tracts in the folded RG4 by 2-methylnicotinic acid imidazolide (NAI) (fig. S2) (11-14), and therefore detects folded RG4 directly. Arabidopsis seedlings grown at $22^{\circ} \mathrm{C}$ were treated for 2 hours either at $4{ }^{\circ} \mathrm{C}$ or $22^{\circ} \mathrm{C}$ (control) followed by treatment with NAI at $4{ }^{\circ} \mathrm{C}$ or $22^{\circ} \mathrm{C}$, respectively, before generating SHALiPE-seq libraries for both groups (fig. S2). Comparable NAI modification efficiencies under different temperatures were achieved, as illustrated (figs. S3 and S4), by both gel-based analysis and SHALiPE-seq library analysis on the 18S rRNA.

Reads distribution for Gs of SHALiPE-seq were characterized using the Gini index, where a high Gini index indicates an uneven distribution of reads on Gs for folded RG4s, whilst a low Gini index indicates an even distribution of unfolded $\operatorname{RG} 4 \mathrm{~s}(11,14)$. We initially established Gini index benchmarks for folded or unfolded RG4s under in vitro conditions with either $\mathrm{K}^{+}$(stabilizes RG4) or $\mathrm{Li}^{+}$(destabilizes RG4) (fig. S2) (11). We then implemented a quantitative algorithm to calculate the folding status in vivo, which we termed 'folding score': a comparison of Gini in vivo with Gini in vitro in the presence of $\mathrm{Li}^{+}$, scaled relative to Gini in vitro with $\mathrm{K}^{+}$vs Gini in vitro with $\mathrm{Li}^{+}$(see methods) (11). The folding scores at $4^{\circ} \mathrm{C}$ were overall significantly higher compared to those at $22^{\circ} \mathrm{C}$ (Fig. $2 \mathrm{~B}, P$ $<10^{-148}$, by paired Student's t-test, Table S4), further supporting that stronger RG4 folding occurs in the cold. In particular, some RG4s showed a switch from unfolded to folded status as the temperature shifted from $22^{\circ} \mathrm{C}$ to $4^{\circ} \mathrm{C}$. In vivo SHALiPE-seq profile examples of RG4s on AT3G20470 at $22^{\circ} \mathrm{C}$ resembled that of the unfolded in vitro benchmark in the presence of $\mathrm{Li}^{+}$, while corresponding in vivo SHALiPE-seq profiles at $4^{\circ} \mathrm{C}$ resembled that of the folded in vitro benchmark in the presence of $\mathrm{K}^{+}$ (Fig. 2C). Therefore, our SHALiPE-seq data along with our immunofluorescence visualizations reinforce the notion that RG4 folding is responsive to cold in living plants.

RG4s have a range of G-quartets and loop lengths $(8,15)$. To test whether different types of RG4s may be favoured in the cold, we compared the folding score differences between $4^{\circ} \mathrm{C}$ and $22^{\circ} \mathrm{C}$ on individual RG4s. We found greater folding score differences for RG4s with three G-quartets (G3-RG4) compared to those with two G-quartets (G2-RG4, Fig. 2D, $P=0.006$, by Student's t-test). In addition, the folding status of RG4s with intermediate lengths from 4 nt to 6 th were more easily enhanced in the 
cold, compared to RG4s with either a very short loop of 2 nt or a very long loop of over 8 nt (Fig. 2E, $P$ $<0.05$, by Student's t-test). Thus, cold conditions are likely to strongly promote the folding of RG4s with a higher number of G-quartets and intermediate loop lengths.

To understand any biological relevance between RG4s and the cold, we performed gene ontology (GO) analysis on genes containing cold-responsive RG4s with higher folding scores upon cold treatment. We found specific transcript-related enrichment in biological functions, such as response to abiotic stimulus, response to temperature stimulus and response to cold (Fig. 2F). Thus, those genes containing cold-responsive RG4s are also likely to function in plant response to cold.

To further explore how these cold-responsive RG4s may affect the plant response to cold, we assessed their molecular functions in regulating gene expression. Extensive studies have suggested that RG4 serves as a translational repressor $(8,11,16)$. Thus, we assessed whether cold-responsive RG4s repress translation in the cold. We compared the translation efficiencies (TEs) of those genes containing coldresponsive RG4s at either $4^{\circ} \mathrm{C}$ and $22^{\circ} \mathrm{C}$. Overall, we observed only a subtle variation $(2 \%)$ and a high correlation between $\mathrm{TE}$ at $4{ }^{\circ} \mathrm{C}$ and $\mathrm{TE}$ at $22^{\circ} \mathrm{C}$ (Fig. $3 \mathrm{~A}, \mathrm{PCC}=0.86$, difference $=2 \%$, Table S5), suggesting cold-responsive RG4s are unlikely to contribute much to translation. We then examined the folding score differences between $4^{\circ} \mathrm{C}$ and $22^{\circ} \mathrm{C}$ of RG4s in different genic regions and found RG4s in the 3'UTR possessed the greatest folding score differences (Fig. 3B, $P=0.01$ for CDS vs 3'UTR, by Student's t-test). Based on previous studies that suggested structural elements in 3'UTRs are likely to regulate mRNA stability (17-19), we hypothesized that cold-responsive RG4s may impact mRNA stability. We measured the RNA stability of the Arabidopsis transcriptome at both $22^{\circ} \mathrm{C}$ and $4{ }^{\circ} \mathrm{C}$ using the transcription arrest assay (Fig. 3C) (20). Upon transcription arrest, the rate of mRNA abundance decline reveals RNA stability, whereby a rapid decrease indicates low stability whilst a slow decrease indicates high stability. Overall, we found a generally slower mRNA abundance decline at $4^{\circ} \mathrm{C}$ compared to $22^{\circ} \mathrm{C}$ (Fig. 3D). Notably, the cold effect of slowing down RNA abundance decline was found to be highest for transcripts with cold-responsive RG4s in 3'UTRs, compared to those transcripts without RG4s (non-RG4), or with cold-responsive RG4s in 5'UTR and/or CDS regions (Fig. 3D). The transcription arrest profiles for individual mRNAs are illustrated for AT1G13390, AT4G32020 and AT5G24930 along with their corresponding qRT-PCR validations (fig. S5).

We then derived the mRNA decay rate for individual mRNAs with cold-responsive RG4s at both $4^{\circ} \mathrm{C}$ and $22^{\circ} \mathrm{C}$ (Table S6). The mRNA decay rates at $4^{\circ} \mathrm{C}$ altered dramatically compared to those at $22^{\circ} \mathrm{C}$ (Fig. $3 \mathrm{E}, \mathrm{PCC}=0.02$ ), and generally showed slower mRNA decay rates in the cold. We subsequently calculated the decay rate differences between $4{ }^{\circ} \mathrm{C}$ and $22^{\circ} \mathrm{C}$ and found a significantly greater difference of decay rate between $4^{\circ} \mathrm{C}$ and $22^{\circ} \mathrm{C}$ on transcripts with cold-responsive RG4s in 3'UTR compared to that of transcripts without RG4s or with RG4s in 5'UTR or CDS regions (Fig. 3F, $P$-values $=0.02,0.04$ and 0.03 respectively, by Student's t-test). As mRNA stability directly affects steady-state mRNA abundance, we reasoned that cold enhances the steady-state mRNA abundance of transcripts with cold-responsive RG4s. Indeed, we found a strong increase of mRNA abundance in the 
cold for transcripts with cold-responsive RG4s in the 3'UTRs, rather than nonRG4 transcripts or coldresponsive RG4s in 5'UTR/CDS regions (Fig. 3G, $P=10^{-5}, 0.06$ and 0.04 respectively, by Student's ttest). Collectively, our results suggest cold-responsive RG4s strongly impact mRNA stability rather than mRNA translation. These cold-responsive RG4s in the 3'UTR serve as mRNA stabilizers, reducing mRNA degradation in the cold.

Considering the strong molecular function of these cold-responsive RG4s in 3'UTRs, we reasoned that these cold-responsive RG4s, as mRNA stabilizers, may affect plant phenotypic response to the cold. Of the cold-responsive RG4s present in 3'UTRs, the one with the greatest folding score difference between $4^{\circ} \mathrm{C}$ and $22^{\circ} \mathrm{C}$ was found on $A T 1 G 13390$ (fig. S6A and Table S4), designated as CORG1 (COld-responsive $\underline{\text { RNA }} \underline{\text { G-quadruplex }} \underline{1}$ ), with the annotation encoding a translocase subunit protein (courtesy of The Arabidopsis Information Resource). To further explore whether this CORG1 RG4 contributes to mRNA stabilization in the cold, we constructed the reporter gene, FIREFLYLUCIFERASE (FLUC) fused with the 3'UTR of CORG1 containing the wildtype cold-responsive RG4 (wtRG4) or a disrupted RG4 (mutRG4, Fig. 4A). We then performed transcriptional arrest assays at both $4{ }^{\circ} \mathrm{C}$ and $22^{\circ} \mathrm{C}$ to measure the corresponding mRNA stabilities. The FLUC mRNA with the $3^{\text {'UTR }}$ of CORG1 containing the mutRG4 degraded much more rapidly compared to that containing wtRG4 at $4^{\circ} \mathrm{C}$, while no significant differences were found between these two versions at $22^{\circ} \mathrm{C}$ (Fig. $4 \mathrm{~B}$ ), indicating that this cold-responsive RG4 enhanced mRNA stabilization in cold conditions.

We then reintroduced Arabidopsis genomic DNA of CORG1 containing 3'UTR with either wtRG4 or mutRG4 into the $\operatorname{corg} 1-1$ null mutant (figs. S6, B and C). At $22^{\circ} \mathrm{C}$, the primary root growth of $\operatorname{corg} 1$ 1 was similar to that of wild type Col-0 (Fig. $4 \mathrm{C}$ ). At $4^{\circ} \mathrm{C}$, the root length of $\operatorname{corg} 1-1$ was distinctively longer than that of Col-0, indicating CORG1 represses plant growth under cold conditions. When the corgl-1 mutant was complemented with mutRG4-CORG1, the root length was significantly longer than $w t R G 4-C O R G 1$ complemented plants at $4^{\circ} \mathrm{C}$, while no significant differences were observed at $22^{\circ} \mathrm{C}$ (Fig. 4C, $P$-values $<0.01$, one-way ANOVA/Tukey HSD post hoc test), suggesting impairment of mutRG4-CORG1 plants in sensing cold. The cold sensitive defects in the mutRG4-CORG1 plants correspond to the more rapid RNA decay and decrease in steady-state CORGI RNA abundance (figs. $\mathrm{S} 6, \mathrm{D}$ and E). Collectively, these results indicate this cold-responsive RG4 regulates CORG1 mRNA stability in the cold and so significantly modulates plant cold-responsive growth.

Our broad and deep investigations of nucleotide composition across the plant kingdom promote the discovery of RNA G-quadruplex structure serving as a molecular marker shaping plant environmental adaptation. RNA G-quadruplexes embedded across the plant transcriptome globally facilitate stabilizing RNA molecules in response to cold (Fig. 4D). Hence, our results suggest that RNA structure, as a key regulator of gene expression (21-23), may have evolved due to selection pressures arising from distinct temperature environments. Our work therefore advances fundamental understanding of the molecular mechanisms underlying species adaptation, translation of this conceptual advance to molecular engineering strategies could help to address global climate change challenges indicated by 
bioRxiv preprint doi: https://doi.org/10.1101/2022.03.04.482910; this version posted March 4, 2022. The copyright holder for this preprint (which was not certified by peer review) is the author/funder. All rights reserved. No reuse allowed without permission.

continuing increases in the frequency, intensity and duration of extreme low-temperature events $(24$, 25). 
A

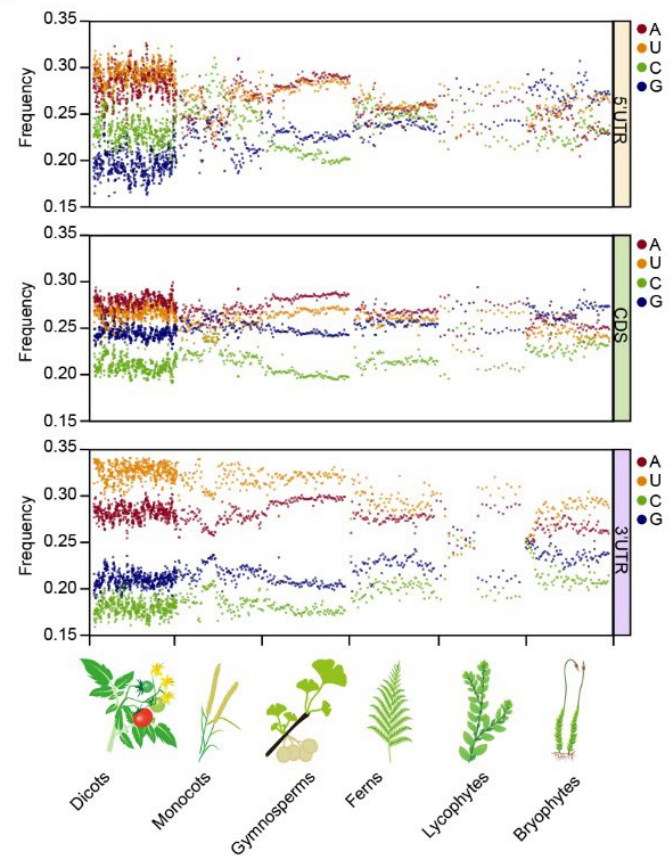

B

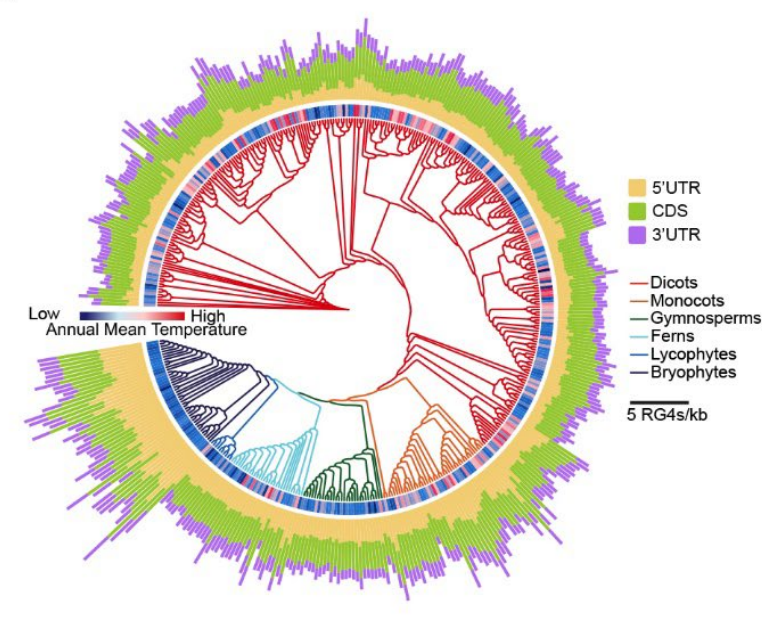

C

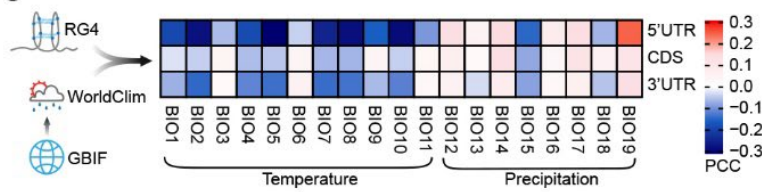

Fig. 1. Comparison of transcriptomic guanine (G) frequencies and RNA G-quadruplex

\section{frequencies exhibit climatic signatures of plant adaptation.}

(A) Scatter plot showing the frequency of each nucleotide (A: adenine, U: uracil, C: cytosine and G: guanine) in transcriptomes of 906 land plants from the 1000 Plants (1KP Initiative) (6). $n=556,107$, $80,71,21,71$ for dicots, monocots, gymnosperms, ferns, lycophytes and bryophytes, respectively.

(B) RNA G-quadruplex (RG4) frequencies in major clades of land plants. Land plants with over 100 occurrences in Global Biodiversity Information Facility (GBIF) (7) were included (see Methods). $\mathrm{n}=$ 277, 43, 30, 30, 10, 43 for dicots, monocots, gymnosperms, ferns, lycophytes and bryophytes, respectively. The corresponding annual mean temperatures for habitats of plant species were colourcoded.

(C) Heat plot showing the Pearson Correlation Coefficients (PCCs) between RG4 frequency in plant transcriptomes and associated bioclimatic variables related to plant habitats. PCCs with a $P$-value less than a threshold of 0.01 were retained. Plant habitats were sourced from the GBIF, while associated bioclimatic variables were derived from the WorldClim database (full details see Materials and Methods). Bioclimatic variable names are listed in Methods, such as BIO1: annual mean temperature; BIO12: annual precipitation etc., as explained by WorldClim. 
A

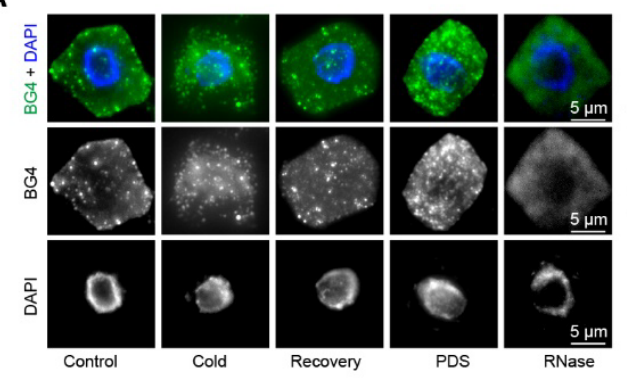

B

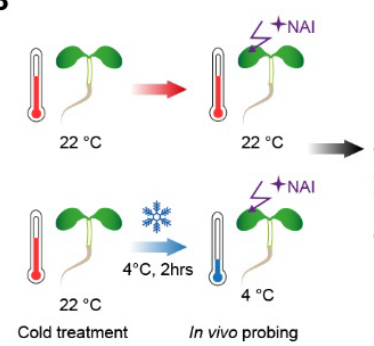

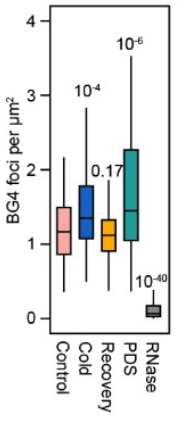

D

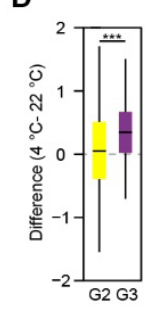

C

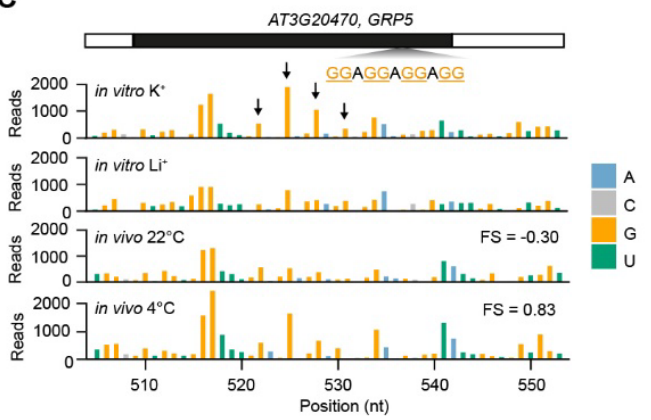

F

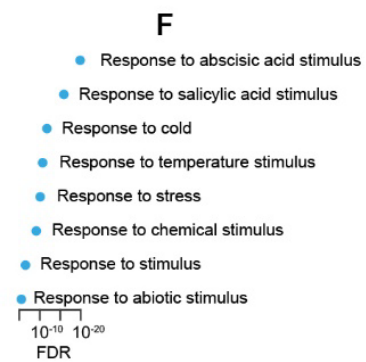

E
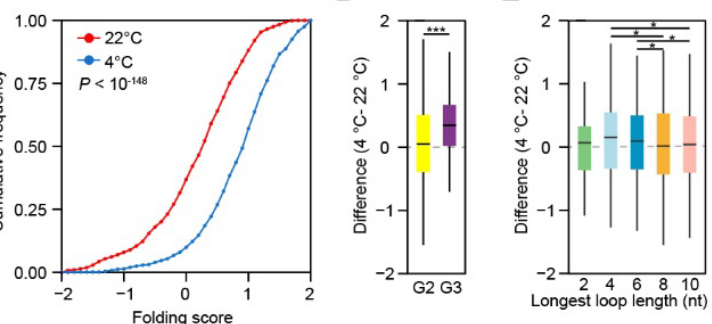

Fig. 2. Cold promotes RNA G-quadruplex folding in Arabidopsis.

(A) Immunofluorescence detection of G-quadruplex (RG4) with BG4 antibody in Arabidopsis under different thermal conditions. Arabidopsis seedlings were grown at $22^{\circ} \mathrm{C}$ (Control) and were i) treated at $4{ }^{\circ} \mathrm{C}$ for 2 hours (Cold); or ii) returned to $22^{\circ} \mathrm{C}$ for 2 hours after cold treatment (Recovery); or iii) treated with $10 \mu \mathrm{M}$ pyridostatin (PDS); or iv) treated with RNase cocktail (RNase). DAPI indicates the nucleus signal. Statistical analysis was performed using more than 80 cells from 3 individual seedlings for each treatment, significance tested by Student's t-test in comparison to Control.

(B) Comparison of RG4 folding by SHALiPE-seq in plants grown at $22^{\circ} \mathrm{C}$ and treated either at $4{ }^{\circ} \mathrm{C}$ or $22^{\circ} \mathrm{C}$, respectively, $\mathrm{n}=817, P<10^{-148}$, by Student's t-test.

(C) SHALiPE-seq profiles of the RG4s on AT3G20470 (GRP5). High reads on last Gs (dark arrow) are compared between in vitro benchmarks: either with $\mathrm{K}^{+}$( $\mathrm{RG} 4$ folded) or $\mathrm{Li}^{+}$(RG4 unfolded). In vivo profiles show unfolded state at $22^{\circ} \mathrm{C}$ (resembles benchmark with $\mathrm{Li}^{+}$) but folded state at $4^{\circ} \mathrm{C}($ resembles that with $\mathrm{K}^{+}$).

(D) Frequency of distinct RG4 motifs comparing folding score differences $\left(4^{\circ} \mathrm{C}-22^{\circ} \mathrm{C}\right)$ between $\mathrm{G} 2$ RG4 and G3-RG4 motifs; $\mathrm{n}=1436,51$ for G2 and G3 sites, respectively, $* * * P=0.006$ by Student's ttest.

(E) Comparison of RG4 folding score difference frequencies $\left(4^{\circ} \mathrm{C}-22^{\circ} \mathrm{C}\right)$ with different $\mathrm{RG} 4$ loop lengths. RG4 sites $\mathrm{n}=104,304,243$, 442, and 343 for loop length of 2nt, 4nt, 6nt, 8nt and 10nt, respectively. $* P<0.05$ by Student's t-test.

(F) Representative gene ontology items of transcripts with cold-responsive RG4s. 
A

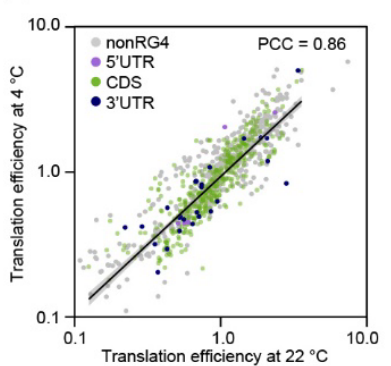

D

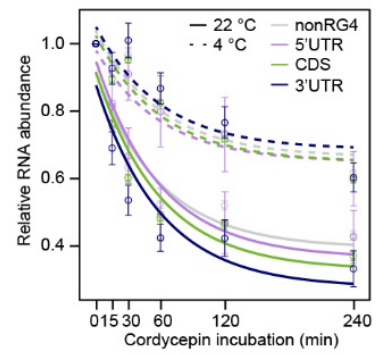

B

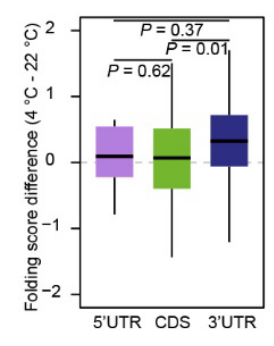

E

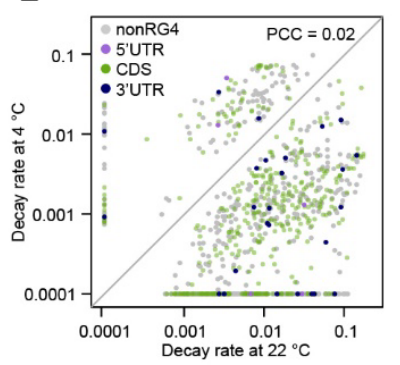

C
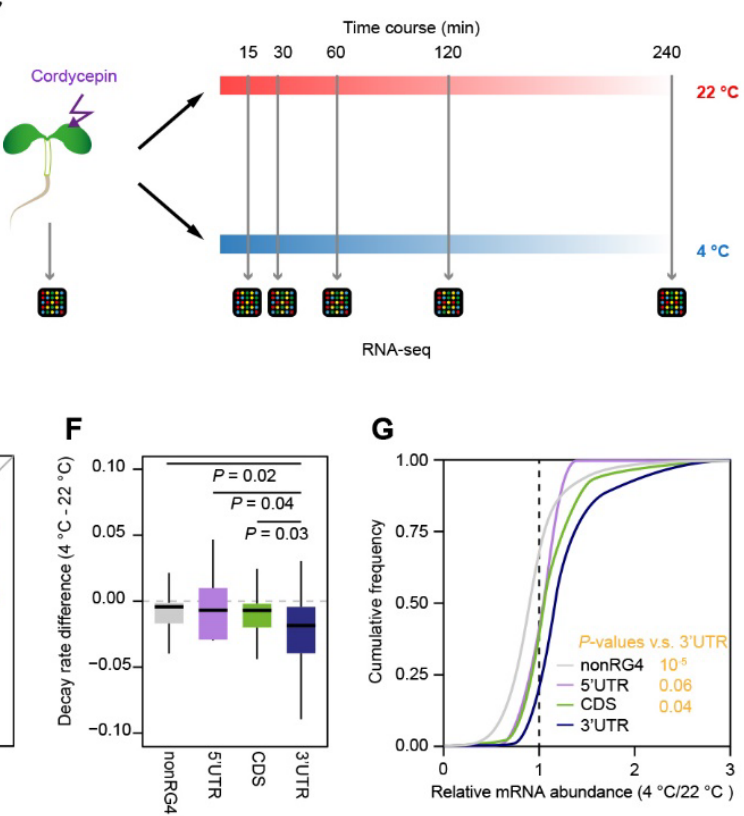

Fig. 3. Cold-responsive RNA G-quadruplex in 3'UTR represses mRNA decay.

(A) Comparison of translation efficiency (TE) at $22^{\circ} \mathrm{C}$ and $4{ }^{\circ} \mathrm{C}$, for transcripts without RG4 (nonRG4), with RG4 in 5'UTR, with RG4 in CDS and with RG4 in 3'UTR. The number of transcripts, $\mathrm{n}=465,6$, 531, 36, for nonRG4, 5'UTR, CDS and 3'UTR respectively.

(B) Comparison of folding score differences $\left(4^{\circ} \mathrm{C}-22^{\circ} \mathrm{C}\right)$ between $\mathrm{RG} 4$ located in different genic regions. The number of RG4 sites, $\mathrm{n}=9,1421,57$ for 5'UTR, CDS and 3'UTR, respectively; $P$-values by Student's t-test.

(C) Schematic of determining RNA stability in Arabidopsis at $22^{\circ} \mathrm{C}$ and $4{ }^{\circ} \mathrm{C}$, by transcriptional arrest analysis with cordycepin incubation.

(D) RNA abundance curves at $22^{\circ} \mathrm{C}$ and $4{ }^{\circ} \mathrm{C}$ for transcripts with cold-responsive RG4s, otherwise in Fig. 3A. Error bar indicates SE of different transcripts.

(E) Comparison of decay rate of transcripts with cold-responsive $\mathrm{RG} 4 \mathrm{~s}$ at $22^{\circ} \mathrm{C}$ and $4{ }^{\circ} \mathrm{C}$, otherwise in Fig. 3A.

(F) Comparison of decay rate differences $\left(4^{\circ} \mathrm{C}-22^{\circ} \mathrm{C}\right)$ on transcripts with cold-responsive RG4s. $P$ value by Student's t-test, otherwise in Fig. $3 \mathrm{~A}$.

(G) Line plot showing relative mRNA abundance at $4{ }^{\circ} \mathrm{C}$ versus $22^{\circ} \mathrm{C}$ for transcripts with coldresponsive RG4s. $P$-values by Student's t-test, otherwise in Fig. 3A. 
A

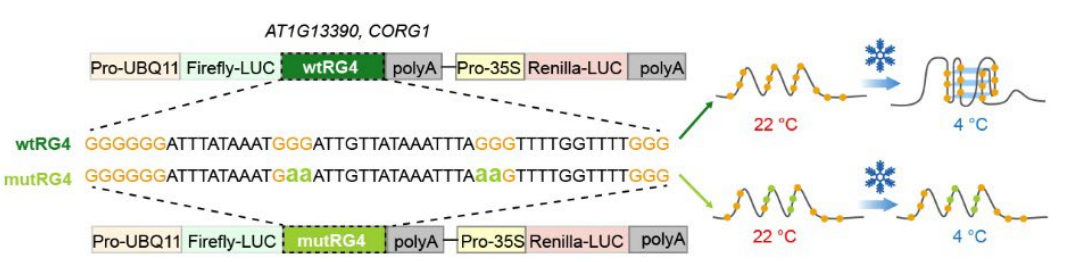

C
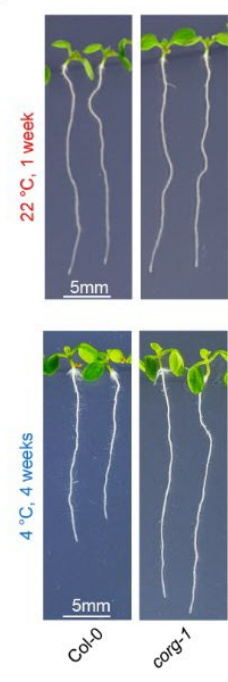
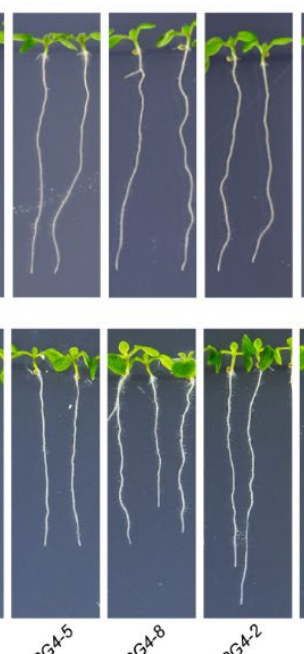
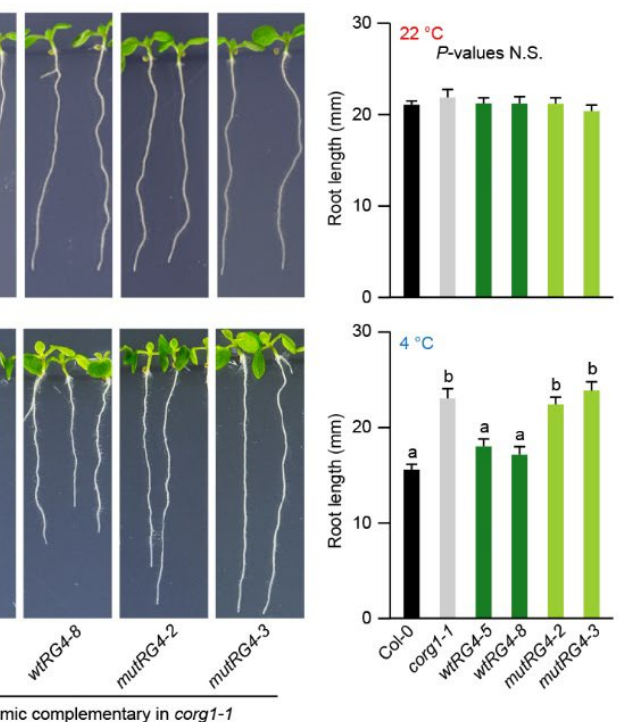

D

B
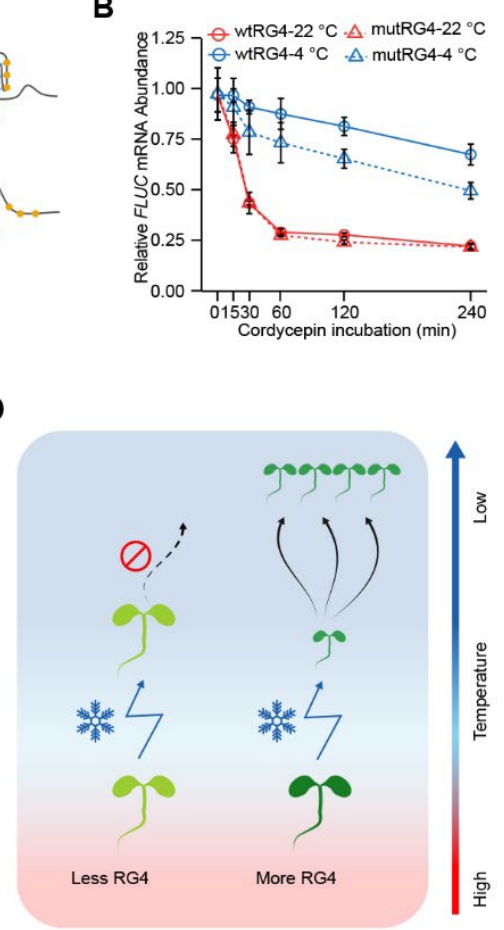

Fig. 4. RNA G-quadruplex regulates plant cold-responsive growth.

(A) Schematic of folding status of wild-type RG4 (wtRG4) and mutated RG4 (mutRG4) on CORG1 $3^{\prime}$ UTR at $22^{\circ} \mathrm{C}$ and $4^{\circ} \mathrm{C}$. The RG4 folding potential was either maintained in wtRG4 or attenuated in mutRG4 by $\mathrm{G}$ to A substitution.

(B) RNA decay curves at $22^{\circ} \mathrm{C}$ and $4^{\circ} \mathrm{C}$ for FIREFLY LUCIFERASE (FLUC) transcripts with wtRG4 or mutRG4, as with the designs shown in Fig. 4A. Error bar indicates SE, $n=4$.

(C) Phenotypes of plants of different genotypes grown at $22^{\circ} \mathrm{C}$ or $4{ }^{\circ} \mathrm{C}$. wtRG4 or mutRG4 denotes corg1-1 mutant complemented with genomic DNA of CORG1 carrying wtRG4 or mutRG4 respectively, as illustrated in Fig. 4A. Comparison was performed on the plants grown vertically on plates at $22^{\circ} \mathrm{C}$ for 1 week, or at $4^{\circ} \mathrm{C}$ for 4 weeks. Significance tested by one-way ANOVA/Tukey HSD post hoc test $(P<0.05), \mathrm{n} \geq 20$, error bar indicates SE.

(D) Model showing the selective enrichment of RG4 driving plant adaptation to cold climates. More RG4s in the plant transcriptome enable higher phenotypic plasticity in cold sensing, therefore shaping plant adaptation to colder climates. 


\section{References and Notes}

1. O. Savolainen, M. Lascoux, J. Merila, Ecological genomics of local adaptation. Nat Rev Genet 14, 807-820 (2013).

2. M. Verdu, J. M. Gomez, A. Valiente-Banuet, C. Schob, Facilitation and plant phenotypic evolution. Trends Plant Sci 26, 913-923 (2021).

3. L. T. Lancaster, A. M. Humphreys, Global variation in the thermal tolerances of plants. Proc Natl Acad Sci U S A 117, 13580-13587 (2020).

4. P. Smarda et al., Ecological and evolutionary significance of genomic GC content diversity in monocots. Proc Natl Acad Sci U S A 111, E4096-4102 (2014).

5. S. Xu, J. Wang, Z. Guo, Z. He, S. Shi, Genomic Convergence in the Adaptation to Extreme Environments. Plant Commun 1, 100117 (2020).

6. I. One Thousand Plant Transcriptomes, One thousand plant transcriptomes and the phylogenomics of green plants. Nature 574, 679-685 (2019).

7. S. E. Fick, R. J. Hijmans, WorldClim 2: new 1-km spatial resolution climate surfaces for global land areas. International Journal of Climatology 37, 4302-4315 (2017).

8. C. K. Kwok, G. Marsico, S. Balasubramanian, Detecting RNA G-Quadruplexes (rG4s) in the Transcriptome. Cold Spring Harb Perspect Biol 10, (2018).

9. G. Biffi, M. Di Antonio, D. Tannahill, S. Balasubramanian, Visualization and selective chemical targeting of RNA G-quadruplex structures in the cytoplasm of human cells. Nat Chem 6, 75-80 (2014).

10. R. Rodriguez et al., A novel small molecule that alters shelterin integrity and triggers a DNAdamage response at telomeres. $J$ Am Chem Soc 130, 15758-15759 (2008).

11. X. Yang et al., RNA G-quadruplex structures exist and function in vivo in plants. Genome Biol 21, $226(2020)$.

12. C. K. Kwok, A. B. Sahakyan, S. Balasubramanian, Structural Analysis using SHALiPE to Reveal RNA G-Quadruplex Formation in Human Precursor MicroRNA. Angew Chem Int Ed Engl 55, 8958-8961 (2016).

13. R. C. Spitale et al., RNA SHAPE analysis in living cells. Nat Chem Biol 9, 18-20 (2013).

14. J. U. Guo, D. P. Bartel, RNA G-quadruplexes are globally unfolded in eukaryotic cells and depleted in bacteria. Science 353, (2016).

15. A. Bedrat, L. Lacroix, J. L. Mergny, Re-evaluation of G-quadruplex propensity with G4Hunter. Nucleic Acids Res 44, 1746-1759 (2016).

16. H. Cho et al., Translational control of phloem development by RNA G-quadruplex-JULGI determines plant sink strength. Nat Plants 4, 376-390 (2018).

17. X. Wu, D. P. Bartel, Widespread Influence of 3'-End Structures on Mammalian mRNA Processing and Stability. Cell 169, 905-917 e911 (2017). 
18. H. Goodarzi et al., Systematic discovery of structural elements governing stability of mammalian messenger RNAs. Nature 485, 264-268 (2012).

19. A. Khong, R. Parker, mRNP architecture in translating and stress conditions reveals an ordered pathway of mRNP compaction. J Cell Biol 217, 4124-4140 (2018).

20. R. S. Sorenson, M. J. Deshotel, K. Johnson, F. R. Adler, L. E. Sieburth, Arabidopsis mRNA decay landscape arises from specialized RNA decay substrates, decapping-mediated feedback, and redundancy. Proc Natl Acad Sci U S A 115, E1485-E1494 (2018).

21. J. A. Cruz, E. Westhof, The dynamic landscapes of RNA architecture. Cell 136, 604-609 (2009).

22. T. R. Cech, The RNA worlds in context. Cold Spring Harb Perspect Biol 4, a006742 (2012).

23. M. Ohtani, Y. Kurihara, M. Seki, M. Crespi, RNA-Mediated Plant Behavior. Plant Cell Physiol 60, 1893-1896 (2019).

24. J. Cohen, L. Agel, M. Barlow, C. I. Garfinkel, I. White, Linking Arctic variability and change with extreme winter weather in the United States. Science 373, 1116-1121 (2021).

25. J. Cohen, K. Pfeiffer, J. A. Francis, Warm Arctic episodes linked with increased frequency of extreme winter weather in the United States. Nat Commun 9, 869 (2018).

Acknowledgments: We thank Prof. Beverley Glover (U. Cambridge), Dr. Sam Brockington (U. Cambridge), Prof. Shiheng Tao (Northwest A\&F University), Prof. Giles Oldroyd (SLCU, Cambridge) and Dame Prof. Caroline Dean (John Innes Centre), Dr. Antony Dodd (John Innes Centre), Prof. Cristobal Uauy (John Innes Centre), Prof. Alison Smith (John Innes Centre) and Dr. Desmond Bradley (John Innes Centre) for discussions with this work. Funding: H.Z. is supported by the National Natural Science Foundation of China (32170229) and the National Key Research and Development Program of China (2021YFF1000900). Y.D. is supported by the United Kingdom Biotechnology and Biological Sciences Research Council (BBSRC: BBS/E/J/000PR9788, BB/L025000/1 and BB/N022572/1), and the European Research Council (ERC: 680324). H.Y. is supported by the Human Frontier Science Program Fellowship (LT001077/2021-L). CKK is supported by Shenzhen Basic Research Project (JCYJ20180507181642811), Research Grants Council of the Hong Kong SAR, China Projects CityU 11100421, CityU 11101519, CityU 11100218, N_CityU110/17, Croucher Foundation Project No. 9509003, State Key Laboratory of Marine Pollution Director Discretionary Fund. Author contributions: Y.D. conceived the study; X.Y., H.Y., J.B.M., C.K.K., H.Z., and Y.D. designed the study; X.Y., S.D., Y.Z., and J.Z. performed the experiments; H.Y., X.Y., S.D. and J.C. did the analyses; H.Z., and Y.D. supervised the analyses; X.Y., H.Y., S.D., J.C., H.Z., and Y.D. wrote the paper with input from all authors. Competing interests: The authors have no competing interests. Data and materials availability: The raw data have been deposited in the Sequence Read Archive (SRA) (https://www.ncbi.nlm.nih.gov/sra) under BioProject ID number PRJNA762705. SHALiPE-seq data in vitro and in vivo at $22^{\circ} \mathrm{C}$ are available under BioProject ID number PRJNA561194 (Yang et al., 2020). All data are available in the main text or the supplementary materials. 
bioRxiv preprint doi: https://doi.org/10.1101/2022.03.04.482910; this version posted March 4, 2022. The copyright holder for this preprint (which was not certified by peer review) is the author/funder. All rights reserved. No reuse allowed without permission.

\section{Supplementary Materials}

Materials and Methods

Figs. S1 to S6

Tables S1 to S7 
Supplementary Materials for

\section{RNA G-quadruplex structure contributes to cold adaptation in plants}

Xiaofei Yang, Haopeng Yu, Susan Duncan, Yueying Zhang, Jitender Cheema, J. Benjamin Miller, Jie Zhang, Chun Kit Kwok, Huakun Zhang, Yiliang Ding

Correspondence to: yiliang.ding@jic.ac.uk

zhanghk045@nenu.edu.cn

\section{This PDF file includes:}

Materials and Methods

Figs. S1 to S6

References 1-20 for supplementary materials

\section{Other Supplementary Materials for this manuscript include the following:}

Captains for Table S1 to Table S7

Table S1: Nucleotide frequency of transcriptomes of land plants in One Thousand Plant Transcriptomes Initiative (1KP)

Table S2: Geographic and bioclimatic features for land plants in One Thousand Plant Transcriptomes Initiative (1KP)

Table S3: RG4 density in land plants in One Thousand Plant Transcriptomes Initiative (1KP)

Table S4: Folding score of RG4s at $22^{\circ} \mathrm{C}$ and $4^{\circ} \mathrm{C}$ in Arabidopsis

Table S5: RNA-seq and Polysome-seq at $22^{\circ} \mathrm{C}$ and $4{ }^{\circ} \mathrm{C}$ in Arabidopsis

Table S6: RNA decay rate at $22^{\circ} \mathrm{C}$ and $4^{\circ} \mathrm{C}$ in Arabidopsis

Table S7: Plant genotypes, primers used in this study 


\section{Materials and Methods}

$\underline{\text { Plants and growth conditions }}$

The Arabidopsis thaliana ecotype columbia (Col-0) and corg1-1 mutant (SALK_097604) with T-DNA insertion were obtained from the Nottingham Arabidopsis Stock Centre (NASC); the homozygous mutant was identified using PCR-based genotyping (1). Arabidopsis seeds were sterilized using 70\% ethanol for $10 \mathrm{~min}$, washed with distilled water for 3 times and plated on half-strength Murashige and Skoog medium supplemented with $1 \%$ sucrose. After standing at $4^{\circ} \mathrm{C}$ for 3 days, the plates were placed in a growth chamber at $22^{\circ} \mathrm{C}$. To complement the mutant, corgl-1 mutant plants were transformed using a floral dipping method (2). Transgenic plants were selected using GM media with $10 \mathrm{mg} / \mathrm{l}$ phosphinotricin.

\section{$\underline{\text { Plasmid construction }}$}

To complement the Arabidopsis mutants with wild-type sequence, a DNA fragment of AT1G13390 was amplified from Col-0 genomic DNA using CloneAmp HiFi PCR Premix (Clontech) with primers listed in Table S7. To complement the Arabidopsis mutants with disrupted RG4 sequence (mutRG4), fragments were amplified by overlap PCR with designed mutations (guanine -> adenine, G -> A) on primers (Table S7) (3). PCR products were further introduced into the XmnI and KpnI digested pB7FWG2.0 with In-Fusion (Clontech). For dual-luciferase analysis, the sequence of 3'UTR of AT1G13390 with or without mutation was cloned into the expression vector inter2 digested with AscI and PstI as introduced with designed primers (Table S7). Sequencing-confirmed vectors were then transformed to Agrobacterium tumefaciens GV3101.

\section{Immunofluorescence detection of RG4}

Arabidopsis seedlings of 5 days after germination (DAG) were fixed in $4 \%$ methanol-free formaldehyde (Thermo Scientific) diluted in nuclease free 1 x PBS (Invitrogen) for 30 minutes, then washed 3 times with $1 \times$ PBS (Invitrogen). Roots were then squashed under coverslips onto slides that had been pretreated with 3-Aminopropylthiethoxysilane (Sigma-Aldrich) to increase tissue adherence (4). Samples were then immersed in liquid nitrogen for around 10 seconds before the coverslips were removed. The tissue was left to dry for $1 \mathrm{hr}$ at room temperature, $1 \times$ PBS with $0.1 \%$ Triton $\mathrm{X}-100$ was added to each slide, incubated for 3 mins following with three washes with $1 \times$ PBS. At this stage RNase treatment was carried out for a subset of + RNase slides by adding 12U RNase A and 200U RNase T1 (Invitrogen) diluted in $1 \times \mathrm{PBS}$ to each slide, and incubated for 1.5 hours at $37^{\circ} \mathrm{C}$ following with three 5 -min washes with $1 \times$ PBS. All slides were immersed in $70 \%$ ethanol for 2 hours at room temperature. After three $1 \times$ PBS washes, $2 \%$ BSA dissolved in $1 \times$ PBS was added to each slide and left to incubate at room temperature for 1 hour. The block was aspirated and anti-DNA/RNA G-quadruplex Mouse Fab 
fragment antibody (BG4 antibody, His-Tagged, Lambda antibody AB00174-1.6, Absolute Antibody) with a dilution of 1:300 in 1× PBS with $2 \%$ BSA was added to each slide and incubated in a dark (5), humid box overnight at $4^{\circ} \mathrm{C}$. Three 5 -min washes with $1 \times \mathrm{PBS}$ were then carried out and 1:1000 diluted Alexa Fluor 647 goat anti-mouse IgG H+L secondary antibody A21235 (Invitrogen) was added to each slide, followed by incubation at room temperature for 1 hour. Two 5-min washes with $1 \times$ PBS were carried out followed by a $30 \mathrm{~min}$ incubation at room temperature with $1 \mu \mathrm{g} / \mathrm{mL}$ DAPI in $1 \times \mathrm{PBS}$, following with three 5-min washes with $1 \times$ PBS and three washes with nuclease-free water. The samples were mounted with ProLong Glass (Thermo Fisher Scientific) under No. 1.5 coverslips (VWR). Root cells were imaged using a 100x objective (NA 1.46) on an inverted ZEISS Elyra PS1 microscope (ZEISS, Oberkochen) equipped with an Andor EM-CCD camera and controlled by ZEN 2.3 SP1 software (ZEISS, Oberkochen). $0.2 \mu \mathrm{m}$ optical Z-sections were carried out and images were obtained using $405 \mathrm{~nm}$ and $642 \mathrm{~nm}$ laser lines. ImageJ plugin RS-FISH was used for automated Gquadruplex quantification as described $(6,7)$. Analysis was carried out on 2D maximum intensity Zprojections for individual cells with default settings apart from optimization of difference-of-gaussian values and intensity threshold. To perform PDS treatment in Arabidopsis, seedlings were incubated with $10 \mu \mathrm{M}$ pyridostatin (PDS) dissolved in half strength of Murashige and Skoog liquid medium for 2 hours. PDS penetration was carried out by vacuum infiltration - three times for 30 seconds and 1 minute break each. To perform cold treatment on Arabidopsis, the plate was placed into growth chamber MIR254-PE (Panasonic) at $4^{\circ} \mathrm{C}$ for 2 hours.

\section{$\underline{\text { In vivo NAI probing of RNA }}$}

The NAI probing buffer was kept in an incubator at the desired temperature overnight before use. NAI probing at $22^{\circ} \mathrm{C}$ was carried out as described in our previous study (8). For NAI probing at $4^{\circ} \mathrm{C}$, plates with 5-DAG etiolated seedlings were treated at $4^{\circ} \mathrm{C}$ for 2 hours. Treated seedlings were harvested in a cold room and incubated with $400 \mathrm{mM}$ NAI at $4^{\circ} \mathrm{C}$ for 15 minutes. NAI was quenched using 5 times of DTT to that of NAI. Seedlings were washed 3 times with distilled water, ground in liquid nitrogen and applied to RNA extraction using RNeasy Plant Mini Kit (Qiagen).

\section{Gel-based analysis of NAI probing}

RNA was extracted after NAI probing. $1 \mu \mathrm{g}$ of total RNA was dissolved in $6 \mu \mathrm{L}$ water, $1 \mu \mathrm{L}$ of $5 \mu \mathrm{M}$ Cy5 modified RT primer for 18S rRNA (listed in Table S7) and $0.5 \mu \mathrm{L}$ of $10 \mathrm{mM}$ dNTPs were denatured at $95^{\circ} \mathrm{C}$ for $3 \mathrm{~min}$. The reaction was cooled down to $50^{\circ} \mathrm{C}$ before adding $2 \mu \mathrm{L}$ of $5 \times$ home-made RT buffer (100 mM Tris (pH 8.3), $500 \mathrm{mM} \mathrm{LiCl}, 15 \mathrm{mM} \mathrm{MgCl}_{2}, 5 \mathrm{mM}$ DTT) and $0.5 \mu \mathrm{L}$ reverse transcriptase Superscript III (Invitrogen) and mixing quickly with a pipette. The RT reaction was incubated at $50{ }^{\circ} \mathrm{C}$ for $20 \mathrm{~min}$ following a staying at $85^{\circ} \mathrm{C}$ for $10 \mathrm{~min}$ to inactivate reverse transcriptase. 
cDNA hybridized RNA was degraded by adding $0.5 \mu \mathrm{L}$ of $2 \mathrm{M} \mathrm{NaOH}$ and incubating at $95^{\circ} \mathrm{C}$ for 10 min. Equal volumes of $2 \mathrm{X}$ stopping dye (95\% formaldehyde, $20 \mathrm{mM}$ EDTA (pH8.0), $20 \mathrm{mM}$ Tris (pH 7.5), orange $\mathrm{G}$ ) were added and incubated at $95^{\circ} \mathrm{C}$ for $5 \mathrm{~min}$. The resultant reaction was kept at $65^{\circ} \mathrm{C}$ and loaded to $8 \%$ Acrylamide:Bis-Acrylamide-Urea gel for electrophoresis. For the sequencing lanes, RNA was dissolved in $5 \mu \mathrm{L}$ water, $1 \mu \mathrm{L} 10 \mathrm{mM}$ of corresponding ddNTP (Roche) was added at the beginning.

\section{Generation of the SHALiPE-seq libraries}

Libraries of SHALiPE-seq were prepared as described (8, 9). PolyA-selected RNA was recovered and reverse transcribed using superscript III (Invitrogen) and RT primer (5'CAGACGTGTGCTCTTCCGATCTNNNNNN3') with home-made RT buffer (20 mM Tris (pH 8.3), $100 \mathrm{mM} \mathrm{LiCl}, 3 \mathrm{mM} \mathrm{MgCl}_{2}, 1 \mathrm{mM}$ DTT). The 3'end of resultant cDNAs were ligated to a ssDNA linker (5'-PhosNNNAGATCGGAAGAGCGTCGTGTAG-/3SpC3/3') using Circligase ssDNA Ligase (Epicentre) at $65^{\circ} \mathrm{C}$ for $12 \mathrm{hrs}$. Product longer than $100 \mathrm{nt}$ was recovered using QIAquick Gel Extraction Kit (Qiagen) after separation of the ligation products with TBE-Urea 10\% Gel (Invitrogen). Purified cDNA was subjected to PCR amplification using KAPA Library Amplification Kits (Roche) with Forward Library primer (5’AATGATACGGCGACCACCGAGATCTACACTCTTTCCCTACACGACGCTCTTCCGATCT3 ') and Reverse primers (5'CAAGCAGAAGACGGCATACGAGATNNNNNNGTGACTGGAGTTCAGACGTGTGCTCTT CCGATC3', where NNNNNN denotes the barcodes, e.g. Index1 is CGTGAT for Illumina sequencing). Three rounds of agarose gel purification were performed to purify the fragments of 200 650 bp using QIAquick Gel Extraction Kit (Qiagen). The libraries were sequenced with Illumina HiSeq 4000 platform by BGI Genomics (Hongkong).

\section{Polysome associated mRNA analysis and RNA-seq}

Polysome associated mRNA analysis was performed as described with modifications $(10,11)$. Briefly, around $500 \mathrm{mg} 5$-DAG etiolated seedlings (grown at $22^{\circ} \mathrm{C}$, with or without 2 hours treatment at $4^{\circ} \mathrm{C}$ ) were harvested and ground into fine powder in liquid nitrogen. The powder was dissolved in $500 \mu \mathrm{L}$ precooled polysome extraction buffer $(200 \mathrm{mM}$ Tris- $\mathrm{HCl}, \mathrm{pH} 8.4,50 \mathrm{mM} \mathrm{KCl}, 1 \%$ deoxycholic acid, $25 \mathrm{mM} \mathrm{MgCl}_{2}, 2 \%$ Polyoxyethylene 10 tridecyl ether, $2 \mathrm{mM}$ DTT, $400 \mathrm{U} / \mathrm{mL}$ recombinant Rnasin, 50 $\mu \mathrm{g} / \mathrm{mL}$ cycloheximide). After incubation on ice for 30 minutes and centrifugation at $13200 \mathrm{rpm}$ for 15 $\min$ at $4{ }^{\circ} \mathrm{C}, 500 \mu \mathrm{L}$ supernatant was transferred to $15-60 \%$ sucrose gradient. Polysomes were fragmented by 4 hours of centrifugation at $40000 \mathrm{rpm}$ in Beckman ST40Ti rotor. Low to high sucrose gradient was collected, taking fractions 1 to 12 . Fractions of 7 to 12 representing the translation level were taken for RNA isolation with TRIzol reagent (Ambion). To perform RNA-seq experiment, around 
$25 \mathrm{mg}$ plant powder was used for direct RNA isolation by RNeasy Plant Mini Kit (Qiagen). Polysomebound RNA or total RNA was subjected to RNA-seq library generation by BGI Genomics following the manufacturer's BGISEQ-500 protocol.

\section{$\underline{\text { Transcriptional arrest }}$}

Transcriptional arrest analysis was performed as described with modifications (12). For analysis in Arabidopsis, seedlings were harvested, and placed into a petri dish with two layers of filter paper and incubation buffer with cordycepin (1mM PIPES, pH 6.25, $15 \mathrm{mM}$ sucrose, $1 \mathrm{mM}$ potassium chloride, $1 \mathrm{mM}$ sodium citrate and $1 \mathrm{mM}$ cordycepin). For reporter assay in tobacco $N$. benthamiana, leaves after 48 hours of agroinfiltration were harvested, and cut into small discs $(\sim 5 \mathrm{~mm} \times 5 \mathrm{~mm})$. To promote the penetration of cordycepin, vacuum infiltration was performed 3 times, for 1 minute each. The Arabidopsis seedlings or tobacco leaf discs incubated with cordycepin were placed either at $22^{\circ} \mathrm{C}$ or $4^{\circ} \mathrm{C}$, and harvested using a time series of $15,30,60,120$ and 240 minutes. For cold treatment experiments, buffer was pre-cooled at $4{ }^{\circ} \mathrm{C}$, vacuum infiltration was performed in a cold room at $4{ }^{\circ} \mathrm{C}$. The plants without cordycepin incubation were harvested as the control, corresponding to 0 minutes of cordycepin incubation. RNA was extracted and subjected to either qRT-PCR or RNA-sequencing.

\section{Quantitative real-time PCR (qRT-PCR)}

RNA was digested using RNase-free TURBO ${ }^{\text {TM }}$ DNase (Ambion). First strand cDNA was synthesized using reverse transcriptase Superscript III (Invitrogen) and oligo dT primer with home-made RT buffer (20 mM Tris (pH 8.3), $100 \mathrm{mM} \mathrm{LiCl,} 3 \mathrm{mM} \mathrm{MgCl}_{2}, 1$ mM DTT). Quantitative qRT-PCR was performed with LightCycler ${ }^{\circledR} 480$ SYBR Green I Master (Roche) using CFX96 Touch Real-Time PCR Detection System (BIORAD) according to the manufacturer's protocol. PP2A (AT1G13320) was used as the internal control. All primers are listed in Table S7.

\section{Phenotype assessment}

To measure primary root length, images of 1 -week seedlings grown at $22^{\circ} \mathrm{C}$ under short-day $(\mathrm{SD}, 8 / 16$ $\mathrm{h}$, light/dark) were captured using a digital camera. The root length of more than 20 seedlings was measured using ImageJ software $(\mathrm{NIH})$. For cold treatment at $4^{\circ} \mathrm{C}$, plates were placed at $22^{\circ} \mathrm{C}$ for 2 days for germination and transferred to $4^{\circ} \mathrm{C}$ for further growth under the same light condition. Images were taken after 4 weeks' growth at $4^{\circ} \mathrm{C}$.

\section{RNA G-quadruplex structure (RG4) prediction}

Plant transcriptomes were obtained from the resource data of the one thousand plant transcriptomes project (13). RNA G-quadruplex features were extracted according to our previous study (8), and further 
assigned to different structural subclasses of G2-RG4 (RG4 with two layers of G-quartet) or G3-RG4 (RG4 with three layers of G-quartet). The RG4 density was calculated by the count of predicted RG4s, normalized to the total amount of all four bases in the transcriptome for individual species.

\section{Bioclimatic variables for plants}

The latitude and longitude of plant geographic distribution were obtained from observations collected by the Global Biodiversity Information Facility (www.gbif.org). The 433 species with over 100 observations were included in further analysis. The nineteen bioclimatic variables at representative locations were extracted from the WorldClim database (14). BIO1:annual mean temperature, $\mathrm{BIO} 2$ : mean diurnal range (mean of monthly ( $\max$ temp - min temp)), BIO3: isothermality (BIO2/BIO7) $(\times 100)$, BIO4: temperature seasonality (standard deviation $\times 100)$, BIO5: $\max$ temperature of warmest month, BIO6: min temperature of coldest month, BIO7: temperature annual range (BIO5-BIO6), BIO8: mean temperature of wettest quarter, BIO9: mean temperature of driest quarter, BIO10: mean temperature of warmest quarter, BIO11: mean temperature of coldest quarter, BIO12: annual precipitation, BIO13: precipitation of wettest month, BIO14: precipitation of driest month, BIO15: precipitation seasonality (coefficient of variation), BIO16: precipitation of wettest quarter, BIO17: precipitation of driest quarter, BIO18: precipitation of warmest quarter, BIO19: precipitation of coldest quarter. We obtained the corresponding climate features from the latitude and longitude of each plant observation and calculated the 10, 25, 50, 75 and 90 quartiles. The Pearson correlation analysis was performed by R scripts, and the corresponding $P$-values were adjusted by Benjamini-Hochberg method (FDR). The lowest FDR among the different quartiles of climate features was used to represent the corresponding features (15).

\section{Alignment of the sequencing reads}

For RNA-seq and polysome-seq libraries, reads were directly used for alignment. For SHALiPE-seq libraries, the first 3 bases at the 5' end (random nucleotides on adaptor for cDNA ligation) of the raw reads were cropped. The alignment was carried out against Arabidopsis transcriptome TAIR10 release using bowtie version 1.0.1 with iterative mapping procedure (16). The minimum read length allowed to map was fixed to 21 bases long (17). The resulting mapped sam files were converted to bam files and indexed using samtools-1.4.1(18). The stop counts were extracted using HTseq v0.7.2 and the code was written in Python v2.7.15. Reads counts of replicates were merged after observing high correlation amongst these.

\section{$\underline{\text { Gini index and folding score calculation }}$}


Gin index was calculated from the SHALiPE-seq libraries with reads number of G residues in G-tract as described $(8,19)$.

Gini $=\frac{\sum_{i=1}^{n} \sum_{j=1}^{n}|r i-r j|}{2 n^{2} \bar{r}}$

$\mathrm{n}$ denotes the number of $\mathrm{G}$ residues in the G-tracts, and ri denotes the reads number in SHALiPE profiling at position $i$.

To calculate the folding score, the regions with Gini (in vitro $\mathrm{K}^{+}$)/ Gini (in vitro $\mathrm{Li}^{+}$) $>=1.1$ and $\mathrm{G}$ residues with average reads count $>=50$ were included.

folding score $=\frac{\operatorname{Gini}(\text { in vivo })-\operatorname{Gini}\left(\text { in vitro } \mathrm{Li}^{+}\right)}{\operatorname{Gini}\left(\text { in vitro } \mathrm{K}^{+}\right)-\operatorname{Gini}\left(\text { in vitro } \mathrm{Li}^{+}\right)}$

$\underline{\text { Gene Ontology Analysis }}$

Enrichment analysis of GO categories was performed online by AgriGo (20). 
A

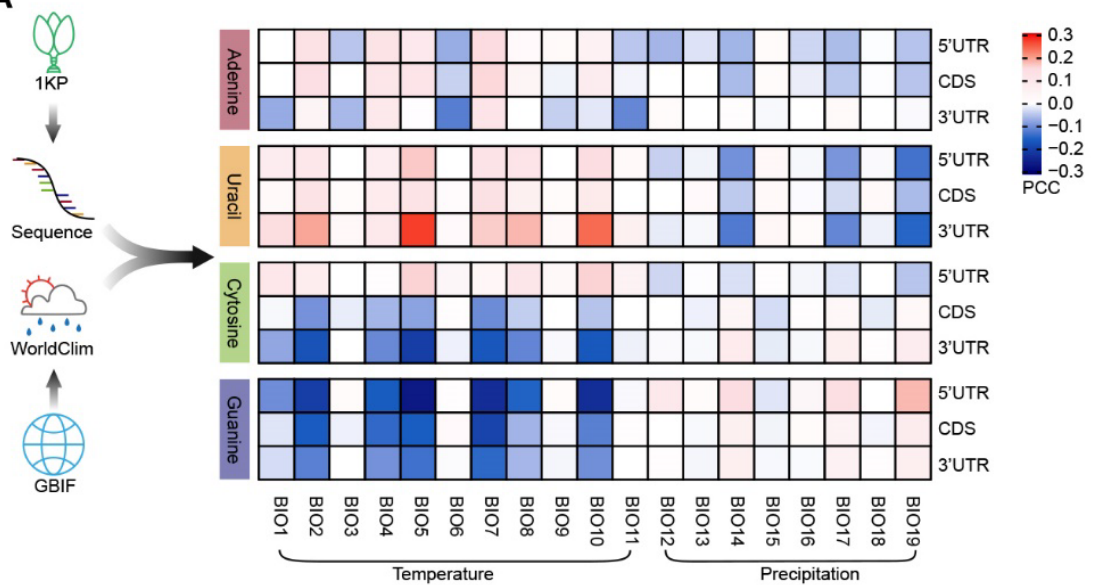

B

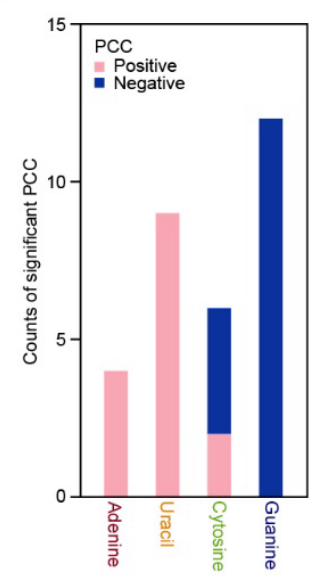

Fig. S1. Transcriptomic nucleotide composition exhibits climatic signatures of plant adaptation.

(A) Heat plot showing the Pearson Correlation Coefficient (PCC) between transcriptomic nucleotide frequency and bioclimatic variables of plant habitats. The frequency of the four nucleotides were calculated in 906 land plants derived from the transcriptomes of the 1000 Plants (1KP). The corresponding plant habitats were sourced from the Global Biodiversity Information Facility (GBIF). The bioclimatic variables of these plant habitats were derived from the WorldClim database (full details see Materials and Methods). BIO1: annual mean temperature; BIO2: mean diurnal range (mean of monthly (max temp - min temp)); BIO3: isothermality $(\mathrm{BIO} 2 / \mathrm{BIO} 7)(\times 100)$; BIO4: temperature seasonality (standard deviation $\times 100$ ); BIO5: $\max$ temperature of warmest month; BIO6: min temperature of coldest month; $\mathrm{BIO} 7$ : temperature annual range (BIO5-BIO6); $\mathrm{BIO}$ : mean temperature of wettest quarter; BIO9: mean temperature of driest quarter; BIO10: mean temperature of warmest quarter; BIO11: mean temperature of coldest quarter; BIO12: annual precipitation; BIO13: precipitation of wettest month; BIO14: precipitation of driest month; BIO15: precipitation seasonality (coefficient of variation); BIO16: precipitation of wettest quarter; BIO17: precipitation of driest quarter; BIO18: precipitation of warmest quarter; BIO19: precipitation of coldest quarter, as explained by WorldClim (https://www.worldclim.org/).

(B) Bar plot showing the counts of significant PCCs between transcriptomic nucleotide frequency and temperature bioclimatic variables. PCCs with a $P$-value less than a threshold of 0.01 were retained. 


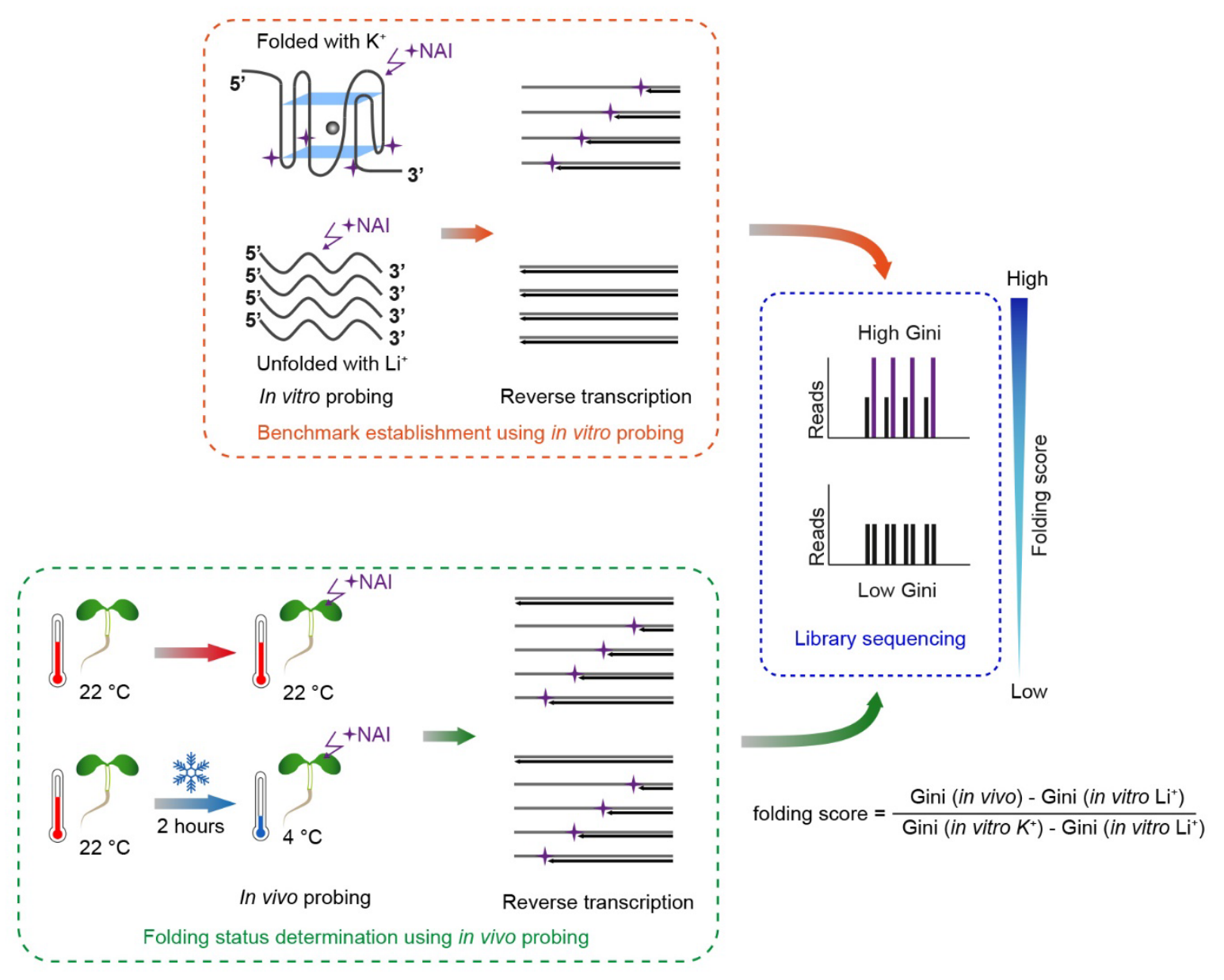

Benchmarks of folded and unfolded RNA G-quadruplex (RG4) were initially established in vitro (top panel) in the presence of $\mathrm{K}^{+}$, which stabilizes RG4 folding, or in the presence of $\mathrm{Li}^{+}$, which destabilizes RG4 folding. Using the SHALiPE in vivo probing method (lower panel), the NAI chemical (indicated by purple star) specially modifies the last $\mathrm{G}$ of the G-tract of folded RG4s, therefore causing high counts of reverse transcription (RT) stops with an uneven distribution, resulting in a high Gini index (middle panel on the right). While for unfolded RG4s, RT stops show an even distribution and low Gini index. For RG4 detection at $22^{\circ} \mathrm{C}$ and $4{ }^{\circ} \mathrm{C}$ in vivo, NAI modification was carried out at the corresponding temperature, followed by reverse transcription, library generation and sequencing. The reads distribution and Gini index at $22^{\circ} \mathrm{C}$ and $4{ }^{\circ} \mathrm{C}$ in vivo were compared to that of $\mathrm{K}^{+}$in vitro, or $\mathrm{Li}^{+}$in vitro, respectively. 
A
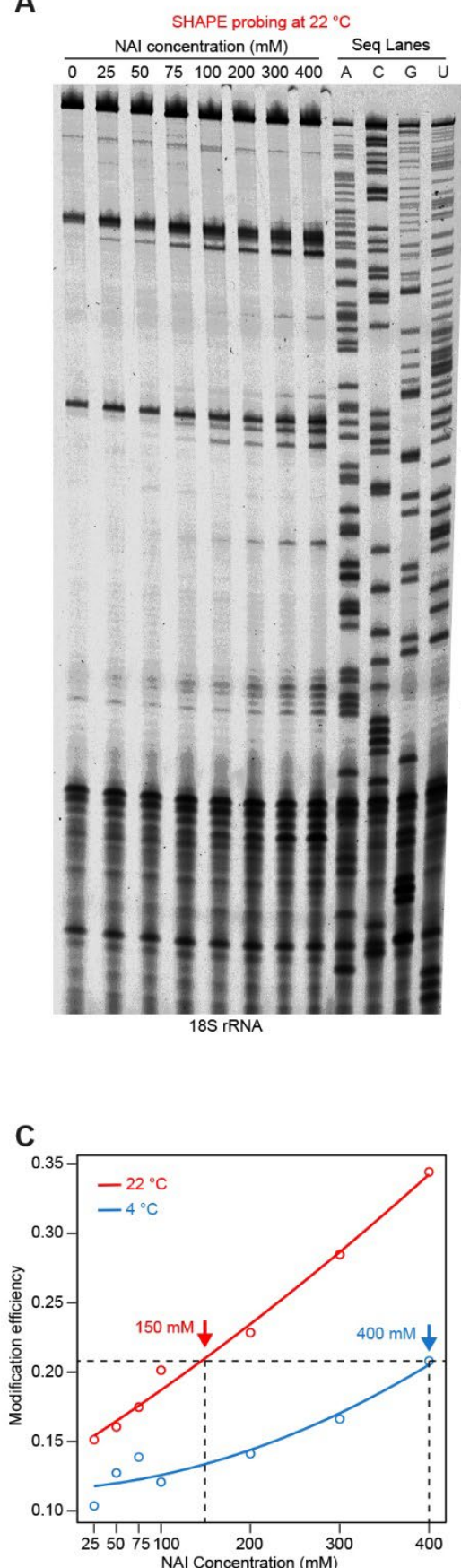

B

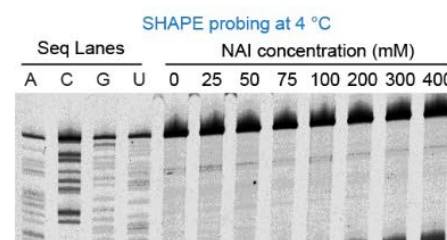

ミミ三ミ$\therefore \equiv$

\section{$-5$}
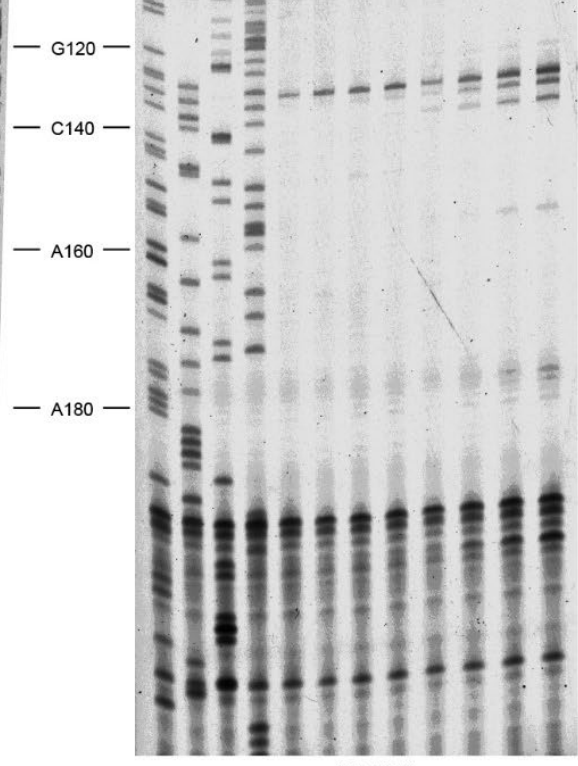

18S rRNA

E

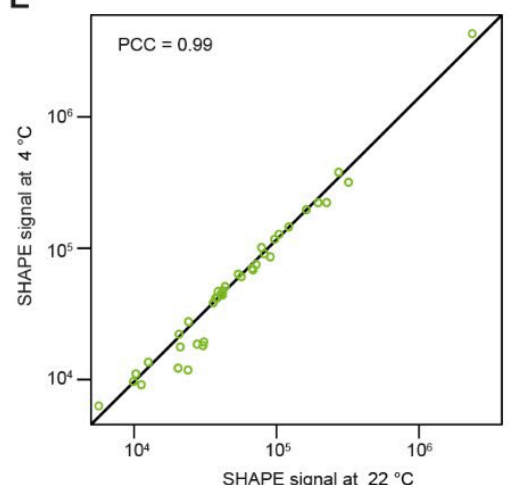

D

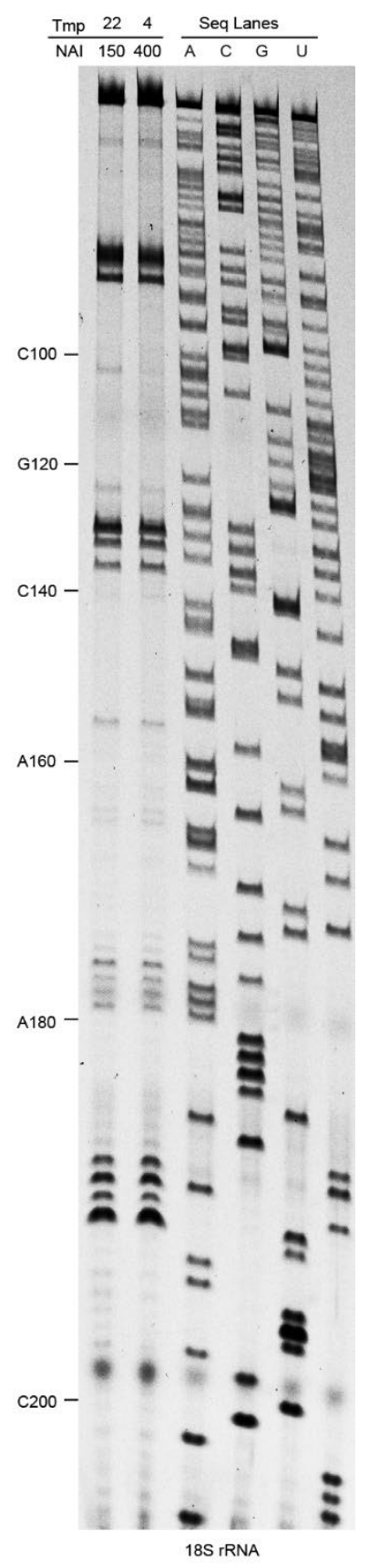

Comparable NAI modification in Arabidopsis at $22^{\circ} \mathrm{C}$ and $4^{\circ} \mathrm{C}$.

(A and B) Gel based analysis of $18 \mathrm{~S}$ rRNA for chemical probing of Arabidopsis at $22^{\circ} \mathrm{C}$ and $4{ }^{\circ} \mathrm{C}$, respectively.

(C) Modification curves of NAI on $18 \mathrm{~S}$ rRNA at $22^{\circ} \mathrm{C}$ and $4{ }^{\circ} \mathrm{C}$. Modification efficiency was calculated by normalizing the signal of modified nucleotides to that of the whole lane in Fig. S3A and Fig. S3B.

(D and E) Comparison of chemical probing in vivo at $22^{\circ} \mathrm{C}$ and $4{ }^{\circ} \mathrm{C}$. Gel based analysis shows comparable NAI probing profile of 18S rRNA (D) and high Pearson Correlation Coefficient (E, PCC $=0.99$ ), with concentrations of $150 \mathrm{mM} \mathrm{NAI}$ at $22^{\circ} \mathrm{C}$ and $400 \mathrm{mM} \mathrm{NAI}$ at $4{ }^{\circ} \mathrm{C}$, as determined in Fig. S3C. 
A
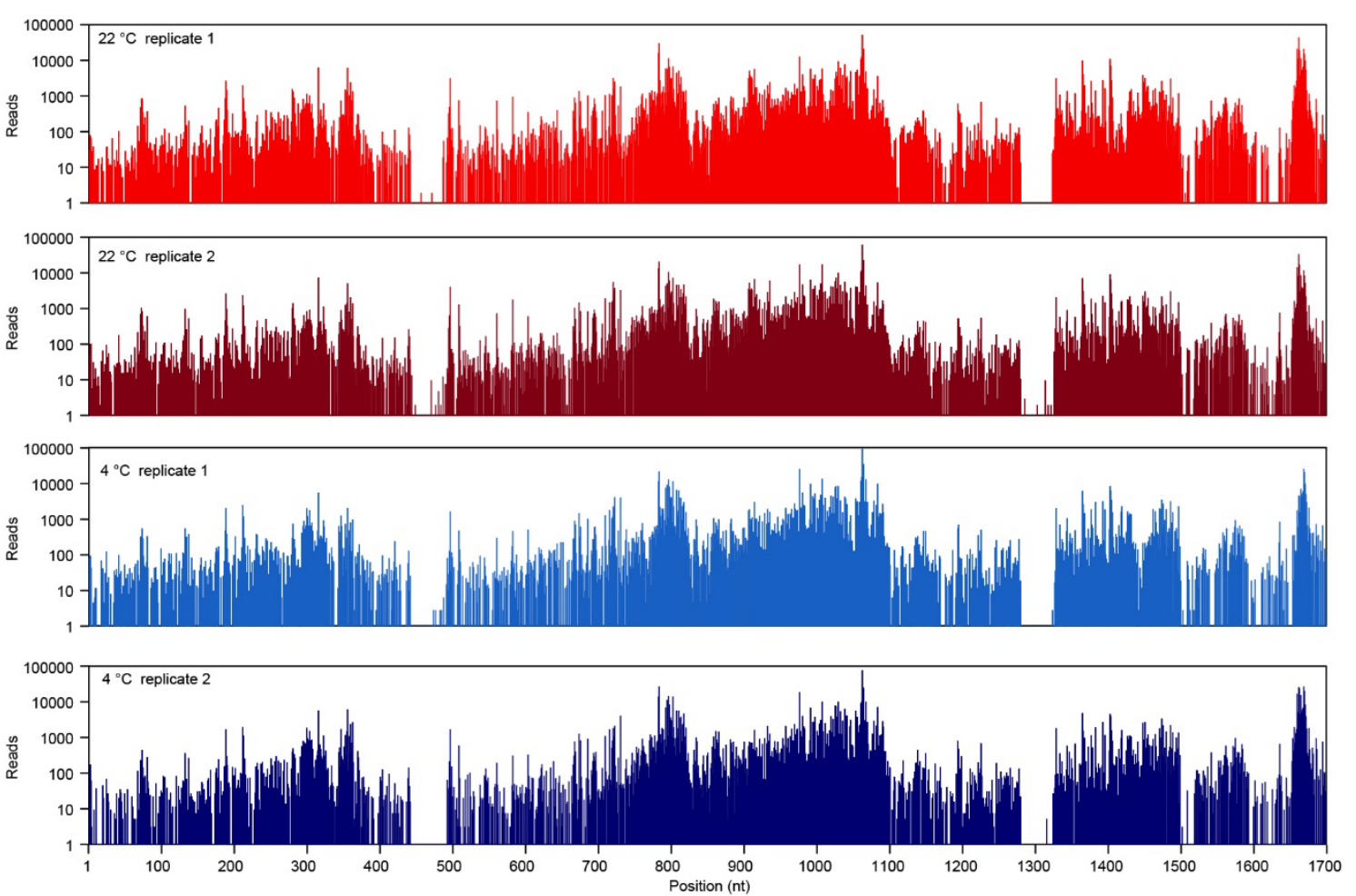

B

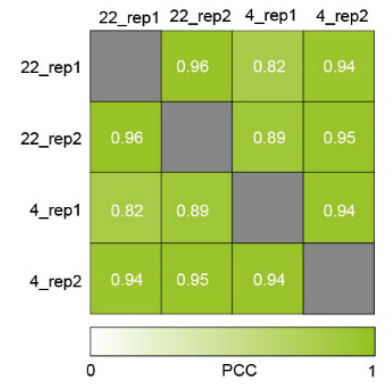

C
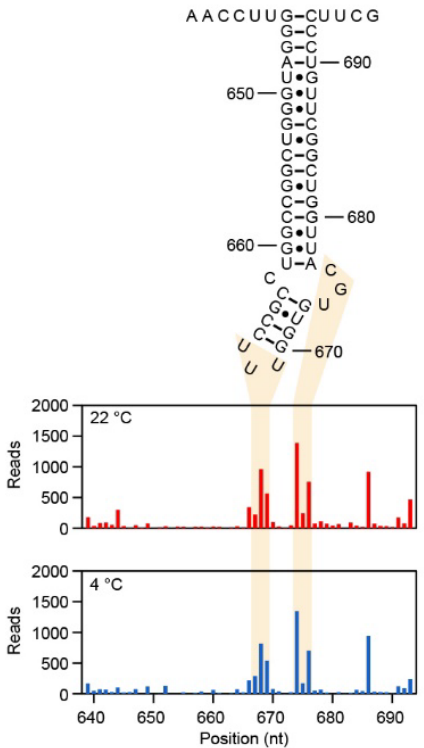

D
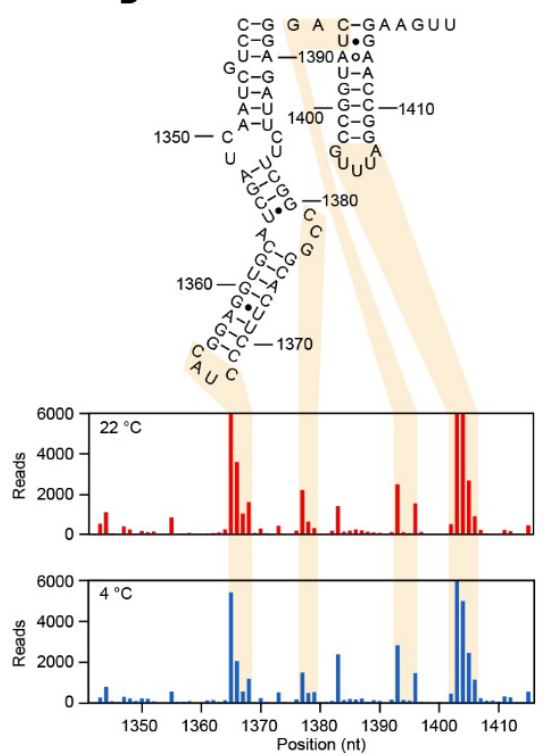

Fig. S4. Robust and accurate determination of RNA structure using SHALiPE-seq at $22^{\circ} \mathrm{C}$ and $4^{\circ} \mathrm{C}$.

(A) The RT-stops of SHALiPE-seq on each nucleotide of $18 \mathrm{~S}$ rRNA at $22^{\circ} \mathrm{C}$ and $4{ }^{\circ} \mathrm{C}$.

(B) High correlations of RT-stops between independent biological replicates and different temperatures.

(C and D) High agreement between SHALiPE-seq profile and phylogenetic structure on 18S rRNA. The unpaired regions in the phylogenetic structure showing high RT-stops at $22^{\circ} \mathrm{C}$ and $4{ }^{\circ} \mathrm{C}$ are highlighted by light orange. 
A

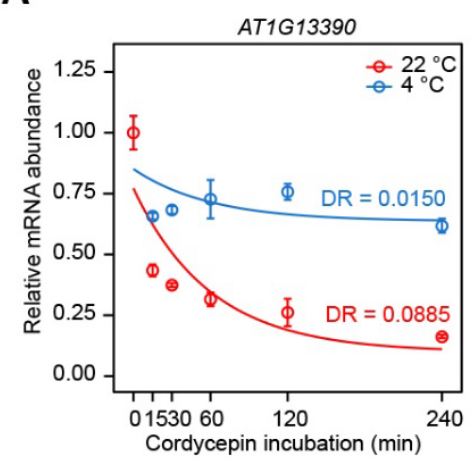

D

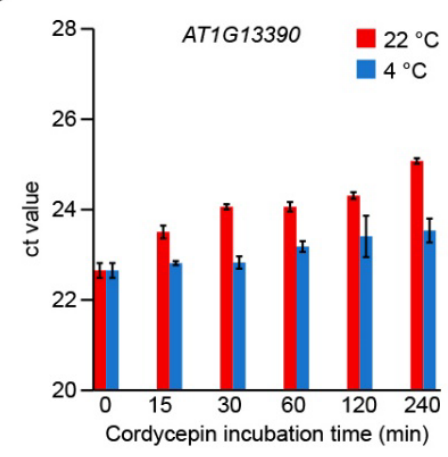

G

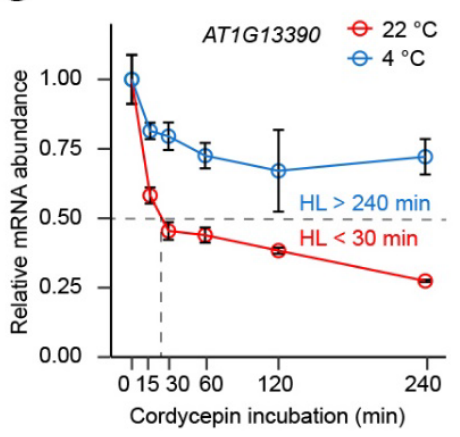

J

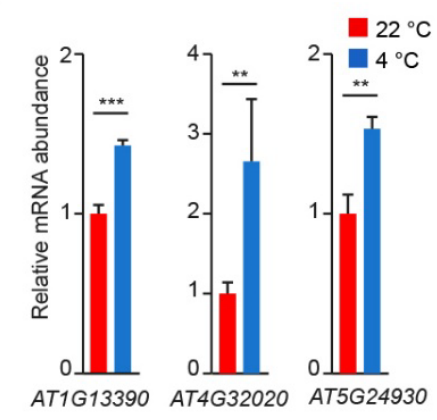

B

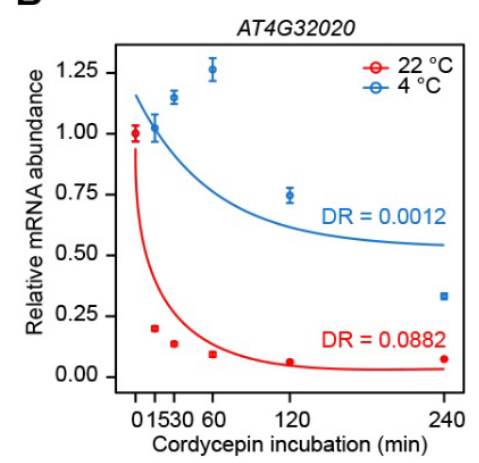

E

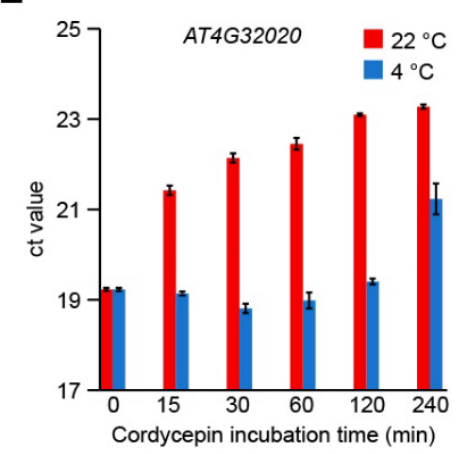

H

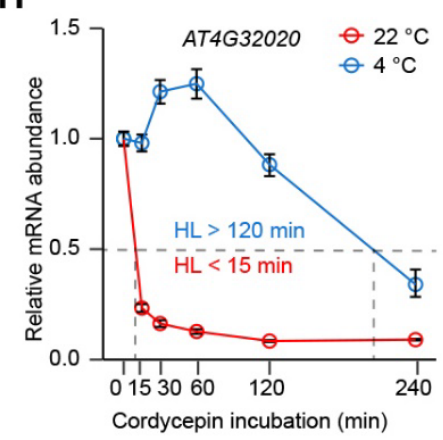

C

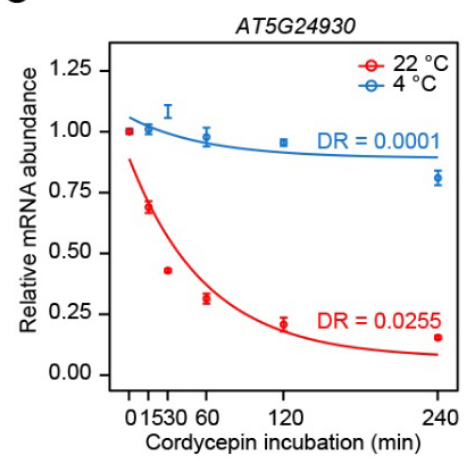

F

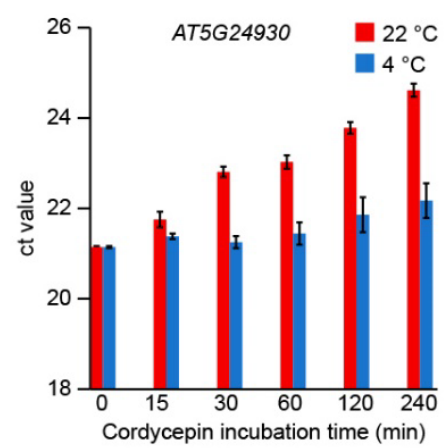

I

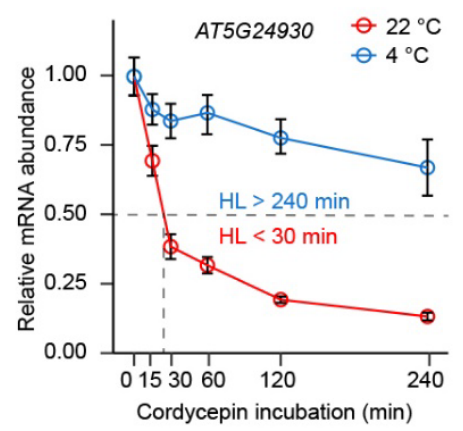

Fig. S5. RG4 in 3'UTR represses mRNA decay and increases mRNA abundance in cold.

(A-C) Line plot showing RNA abundance profiles with transcriptional arrest at $22^{\circ} \mathrm{C}$ or $4^{\circ} \mathrm{C}$ for selected transcripts AT1G13390, AT4G32020 and AT5G24930 with cold-responsive RG4 in 3'UTRs. For these transcripts, the decay rate (DR) was significantly smaller at $4{ }^{\circ} \mathrm{C}$ compared to that at $22^{\circ} \mathrm{C}$, indicating 
slower mRNA decay in the cold. Data were extracted from RNA-seq experiments, error bar indicates SE of 3 biological replicates.

(D-F) Validation of RNA decay using qRT-PCR for selected transcripts at $22^{\circ} \mathrm{C}$ and $4{ }^{\circ} \mathrm{C}$. For AT1G13390 (D), AT4G32020 (E) and AT5G24930 (F), ct values strongly increased according to transcriptional arrest duration at $22^{\circ} \mathrm{C}$, suggesting a significant decrease of mRNA abundance with high decay rates at $22^{\circ} \mathrm{C}$. The ct values at $4^{\circ} \mathrm{C}$ increased very slowly, suggesting high stability of mRNA abundance with slow decay at $4^{\circ} \mathrm{C}$.

(G-I) Line plot showing RNA abundance profiles of selected transcripts with transcriptional arrest at $22^{\circ} \mathrm{C}$ or $4^{\circ} \mathrm{C}$. Relative mRNA abundance of $A T 1 G 13390(\mathbf{G}), A T 4 G 32020(\mathbf{H})$ and $A T 5 G 24930(\mathbf{I})$ was normalized to the RNA abundance before transcriptional arrest, using the data shown in Fig. S5D-S5F. AT1G13320 (PP2A) was used as an internal control. HF: half-life, error bar indicates SE of 3 biological replicates.

(J) Comparison of mRNA abundance at $22^{\circ} \mathrm{C}$ and $4{ }^{\circ} \mathrm{C}$ for selected transcripts with cold-responsive RG4 in 3'UTR. RNA abundance was normalized to internal control of AT1G13320, error bars indicate SE of 3 biological replicates. 
A

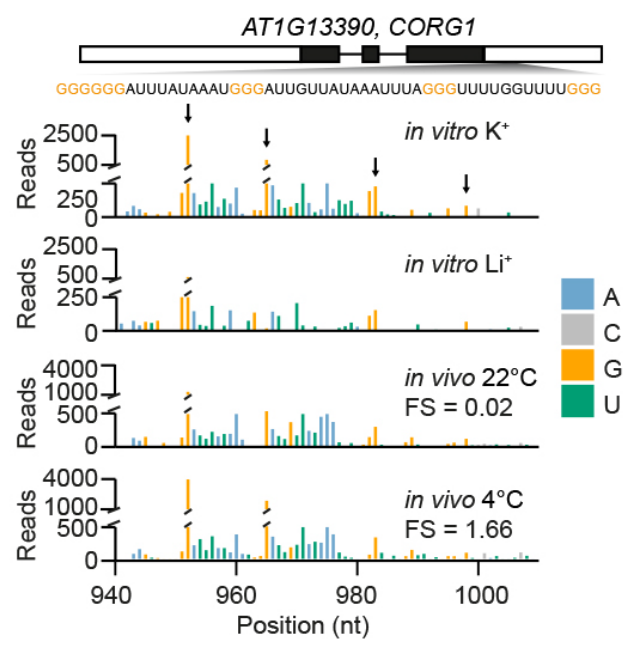

D

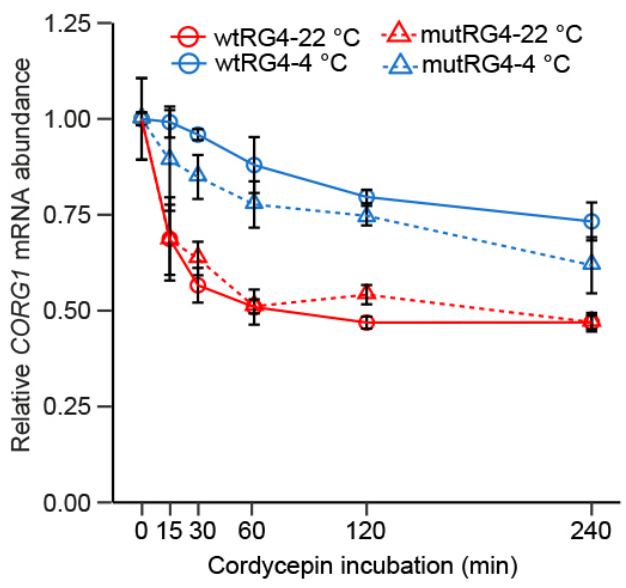

B
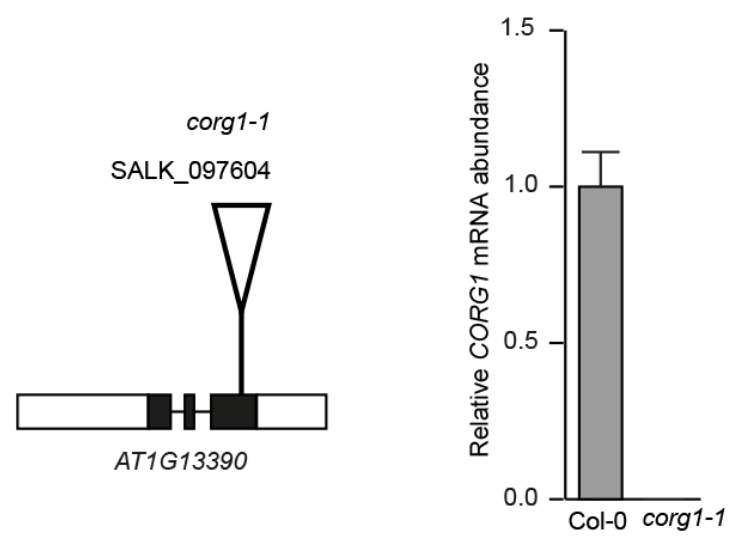

E

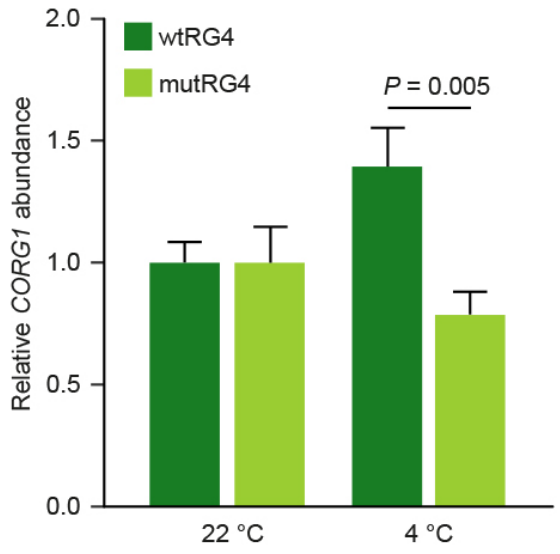

(A) SHALiPE-seq profiles of the RG4s in 3'UTR of AT1G13390 (CORG1). High reads on last Gs (dark arrow) are shown in vitro with $\mathrm{K}^{+}$, compared to that in vitro with $\mathrm{Li}^{+}$. In vivo profiles show unfolded state at $22^{\circ} \mathrm{C}$ resembles that with $\mathrm{Li}^{+}$, but folded state at $4{ }^{\circ} \mathrm{C}$ resembles that with $\mathrm{K}^{+}$. FS: folding score.

(B) Schematic diagram of CORG1 showing the T-DNA insertion site of corg1-1 (SALK_097604).

(C) Relative mRNA abundance of CORG1 in Col-0 and corg1-1 plants indicating corg1-1 is a null mutant, error bar indicates SE of 3 biological replicates.

(D) RNA decay curves at $22^{\circ} \mathrm{C}$ and $4^{\circ} \mathrm{C}$ for endogenous CORG1 transcripts with 3'UTR carrying wtRG4 or mutRG4. Relative mRNA abundance was normalized to the RNA abundance before transcriptional arrest with cordycepin incubation, according to internal control of $P P 2 A$. Error bar indicates SE of 4 biological replicates.

(E) Relative mRNA abundance of CORG1 at $22^{\circ} \mathrm{C}$ and $4{ }^{\circ} \mathrm{C}$ in complemented $\operatorname{corg} 1-1$ mutant using genomic DNA sequence of CORG1 carrying wtRG4 or mutRG4 in 3'UTR, respectively. Error bar indicates SE of 4 biological replicates. 


\section{References}

1. B. C. C. O’Malley R.C., Ecker J.R., in Plant Functional Genomics. Methods in Molecular Biology, S. A. Alonso J., Ed. (Humana Press, New York, NY, 2015), vol. 1284.

2. X. Zhang, R. Henriques, S. S. Lin, Q. W. Niu, N. H. Chua, Agrobacterium-mediated transformation of Arabidopsis thaliana using the floral dip method. Nat Protoc 1, 641-646 (2006).

3. K. L. Heckman, L. R. Pease, Gene splicing and mutagenesis by PCR-driven overlap extension. Nat Protoc 2, 924-932 (2007).

4. L. L. Richardson, M. Dym, Improved adhesiveness of polyester wax sections for immunocytochemistry. Biotechniques 17, 846-848 (1994).

5. G. Biffi, M. Di Antonio, D. Tannahill, S. Balasubramanian, Visualization and selective chemical targeting of RNA G-quadruplex structures in the cytoplasm of human cells. Nat Chem 6, 75-80 (2014).

6. C. A. Schneider, W. S. Rasband, K. W. Eliceiri, NIH Image to ImageJ: 25 years of image analysis. Nat Methods 9, 671-675 (2012).

7. E. Bahry et al., RS-FISH: Precise, interactive and scalable smFISH spot detection using Radial Symmetry. bioRxiv, 2021.2003.2009.434205 (2021).

8. X. Yang et al., RNA G-quadruplex structures exist and function in vivo in plants. Genome Biol 21, 226 (2020).

9. Y. Ding, C. K. Kwok, Y. Tang, P. C. Bevilacqua, S. M. Assmann, Genome-wide profiling of in vivo RNA structure at single-nucleotide resolution using structure-seq. Nat Protoc 10, 1050-1066 (2015).

10. W. Li et al., EIN2-directed translational regulation of ethylene signaling in Arabidopsis. Cell 163, 670-683 (2015).

11. A. Missra, A. G. von Arnim, Analysis of mRNA translation states in Arabidopsis over the diurnal cycle by polysome microarray. Methods Mol Biol 1158, 157-174 (2014).

12. R. S. Sorenson, M. J. Deshotel, K. Johnson, F. R. Adler, L. E. Sieburth, Arabidopsis mRNA decay landscape arises from specialized RNA decay substrates, decapping-mediated feedback, and redundancy. Proc Natl Acad Sci U S A 115, E1485-E1494 (2018).

13. I. One Thousand Plant Transcriptomes, One thousand plant transcriptomes and the phylogenomics of green plants. Nature 574, 679-685 (2019).

14. S. E. Fick, R. J. Hijmans, WorldClim 2: new 1-km spatial resolution climate surfaces for global land areas. International Journal of Climatology 37, 4302-4315 (2017).

15. P. Smarda et al., Ecological and evolutionary significance of genomic GC content diversity in monocots. Proc Natl Acad Sci U S A 111, E4096-4102 (2014).

16. B. Langmead, Aligning short sequencing reads with Bowtie. Curr Protoc Bioinformatics Chapter 11, Unit 1117 (2010). 
17. M. Norris et al., FoldAtlas: a repository for genome-wide RNA structure probing data. Bioinformatics 33, 306-308 (2017).

18. H. Li et al., The Sequence Alignment/Map format and SAMtools. Bioinformatics 25, 20782079 (2009).

19. J. U. Guo, D. P. Bartel, RNA G-quadruplexes are globally unfolded in eukaryotic cells and depleted in bacteria. Science 353, (2016).

20. Z. Du, X. Zhou, Y. Ling, Z. Zhang, Z. Su, agriGO: a GO analysis toolkit for the agricultural community. Nucleic Acids Res 38, W64-70 (2010). 